\title{
Search and Attention: Interactions of the Hippocampal-Septal Axis, Adrenocortical and Gonadal Hormones
}

\author{
ROBERT D. OADES ${ }^{1}$ \\ Institut für Zoologie der T.H., 61 Darmstadt, \\ and Max Planck Institut für Hirnforschung, 6 Frankfurt a.M. 71, German F.R. ${ }^{2}$
}

(Received 2 October 1978)

\begin{abstract}
OADES, R. D. Search and attention: Interactions of the hippocampal-septal axis, adrenocortical and gonadal hormones. NEUROSCI. BIOBEHAV. REV. 3(1) 31-48, 1979.- The phenomenon of attention is treated in terms of the ability to select some sensory input channels over others by the central nervous system for further processing and behavioural organisation. Studies of birds and mammals are reviewed to illustrate two major points. The physiological interaction of the hippocampus and septum modulated by ACTH, adrenal and gonadal steroid hormones have an important influence on the selective aspects of perception. The theme is developed that some of these interactions mediate one of the attributes of an attention process; namely the ability to direct attention to salient stimuli to the exclusion of irrelevant background.
\end{abstract}

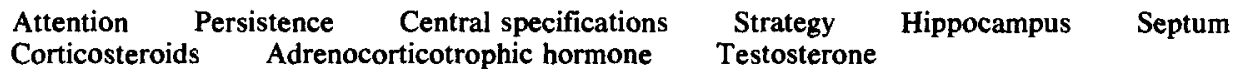

OVER 40 years ago Krechevsky [87] observed that at a given time rats will learn about the correctness of some but not all sensory cues whilst trying to solve a discrimination problem. Animals lack the capacity to process information about all the stimuli falling on the sensorium. To the extent that they process information about stimulus values from one stimulus dimension, they may process some but will not process the equally available stimulus values from other dimensions [95]. This is not an haphazard process, some stimuli are especially salient for an individual. Thus the question arises how is an animal capable of selecting from all that it is aware of those aspects of its environment that are significant or potentially relevant.

Attention, the selective aspect of perception [149], is not itself an overt phenomenon capable of direct observation. However the selection of stimulus events located in a particular region of the stimulus field will exert control over behavior and thus it would be supposed that some stimuli will fail to control behavior [147]. Search behavior amongst other things is one manifestation that the selective process is being brought into action.

Haber and Hershenson [64] postulate two organisational strategies for dealing with the complexity and variability of the ambient energy through which an animal might have to search. Firstly only a few recurrent and highly specific configurations that hold clear biological significance might be registered. (The term registration is taken in this article to refer to the driving of cell(s) long enough for the incoming information to be used, alone or in association with other information in the control of behavior.) Perhaps a suitable example is the selectivity of some peripheral frog retinal cells to small dark moving objects which may centrally be designated bugs-food [52]. Secondly an animal may register and order the elements of complex situations according to certain general perceptual rules. For example the operation of such rules is shown by animals in discrimination situations that change their response pattern more easily to intradimensional rather than extradimensional changes of the stimulus [147].

In fact what may most often occur is a mixture, the nature of which may vary among species [64]. Thus in the auditory pathway, a specific cortical neuron may be driven at a given rate by a sound of specific frequency and pressure level. This alone may be registered and come to control behavior. However the influence of one dimension may be modulated by several other "associative neurons" with different properties ("focal properties" [136]), thus providing call selectivity even to a specific complex stimulus.

At the neuronal level the cell may respond according to certain rules. At the level of a population of cells these rules may take the form of conditioning to a configuration of biological significance. There are selective factors here at work that have importance for characterising attention mechanisms, that are other than those that limit the number of sensory input channels at the periphery. These factors are properties of cells and cell populations that lead to the cen-

'I would like to thank the many people whose discussion helped in the preparation of this article. In particular I thank an anonymous referee for helpful suggestions and Dr. H. Scheich for his critical appraisal. I am grateful to the Deutsche Forschungsgemeinschaft for financial support.

${ }^{2}$ Present address: address for reprint requests. 
tral integration and registration of inputs. There are highly specialised neurons with a preference for restricted ranges of spectral and temporal dimensions. One study found 10-28\% of auditory units in the Starling were responsive to only one type of vocalisation [91]. Many forebrain neurons discriminate in a nearly all or none fashion between vocalisations with overlapping acoustic properties. These neurons have intrinsic properties that affect their sensitivity. These properties may be modified by different states of the animal. Many parts of the central nervous system can be conditioned to this selectivity as a result of experience. Thus single unit evoked responses in the auditory cortex can be modified by requiring the animal to perform an auditory or a visual task and by changing the contingencies of reinforcement. Training (or hippocampal stimulation) can modify the neural responsiveness of sensory cortex [84]. It is centrally that the number of input channels is effectively limited in terms of behavioral relevance. The question is the source and nature of this polydimensional or polysensory control.

I shall take two examples to show why one should look at a physiological environment that is strongly influenced by hormones and neurological substrates (e.g., limbic system) for some answers. These examples do not stand on their own, but in the context of the following review.

Human patients with Korsakoff's syndrome suffer widespread discontinuous damage to the temporal and limbic cortices. They tend to respond on a task to a single attribute (often color) and ignore the relevance of other stimulus characteristics [56]. Normal controls will respond to several of the stimulus attributes (on visual and auditory dichotic tasks). Glosser and his colleagues [56] in reporting on the pattern of errors of commission suggested that where a decision process is complicated (e.g., a near match or identification) Korsakoff patients do not analyse all the incoming information, although given time they may solve the task. Thus we have a neurological line of inquiry to follow as to one source of influence on the availability of input channels (namely, the limbic system).

Andrew and Rogers [7] trained young chicks to prefer food grains dyed red as opposed to normal yellow grains. These birds were tested on a checkerboard array of piles of 10 food grains ( 5 red, 5 yellow). Most birds would eat the red in a pile first and then peck a yellow grain. They would then often switch to a new pile. Normal control chicks would usually peck a second non-preferred yellow grain, whereas chicks injected with testosterone would revert to their trained preference and peck a red grain. Clearly there is an influence of the hormone in the selection and determination by the central nervous system of the relevant stimulus attributes.

In this article experiments that investigate the effects of novel stimulation (orientation), learned responses (attention) and stimulus detection (vigilance) in animals will contribute to the discussion (Fig. 1). I will concentrate on the physiological bases involved in the selective aspects of perception (attention) rather than on theoretical issues of information processing. It is both theoretically possible and physiologically likely for input channels to interact either directly (collateral inhibition) or indirectly through a central base (hippocampus, hormonal modulation). The specific nature of the origin of such a postulated control influence (same or another channel) is usually beyond the resolution of the experiments discussed. Therefore little mention will be made to feedback control and instead the simplified dimensions of inhibition and facilitation will be used. The analogy of a fil-

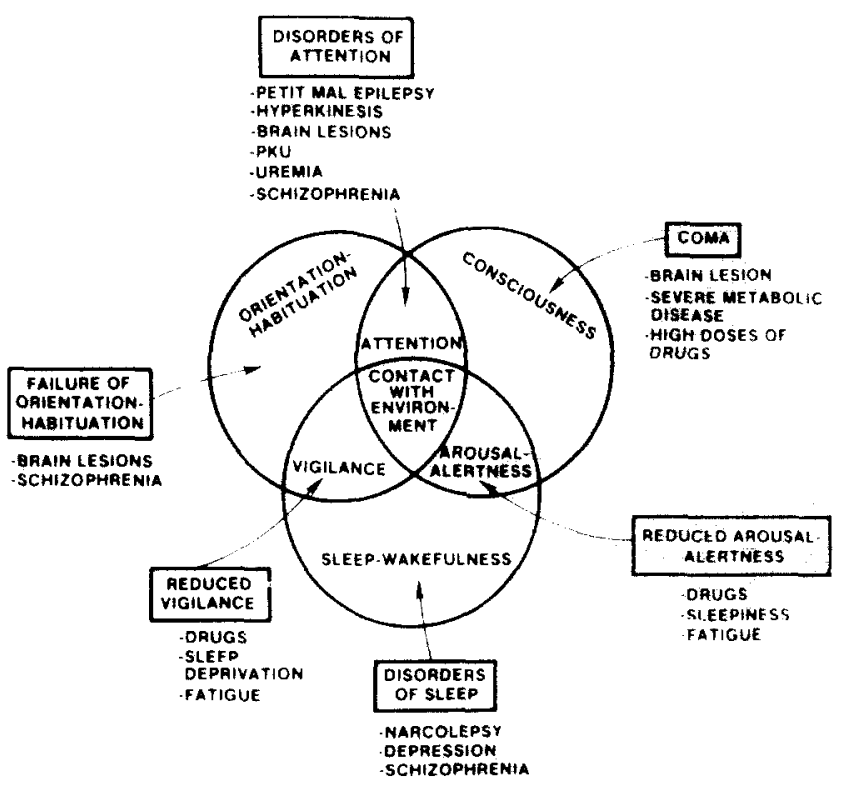

FIG. 1. This diagram shows the relationship and overlap of different fields of research that relate to the concept of attention of an animal to its environment (after Mirsky and Orren [104]).

tering or gating system is retained as it is an attentional system rather than a detailed model that is here discussed.

This paper describes some of the physiological influences in the forebrain on what may be considered the registration process and the rules for the use of registered sets of central specifications for matching features that are salient for an individual in a given situation. Instances where the drive states of aggression, sex, hunger and thirst predominate are not considered here. Thus the influence of steroid hormones and the limbic system form a large part of the following discussion. This does not imply that attentional processes are exclusively influenced by these systems or that these systems only function in attentional processes.

\section{A HIPPOCAMPAL ROLE IN ATTENTION}

\section{Electrophysiological Correlates}

The hippocampus shows distinct electrical frequency patterns that accompany alerting and visual discrimination for reward in a wide range of animals $[1,80]$. This rhythmic slow wave or theta activity (approx. $4-12 \mathrm{~Hz}$ ) is driven from the septum [60]. Theta (e.g., in the cat and rabbit) is generally accompanied by neocortical and behavioral signs of alerting whether this occurs spontaneously in response to sensory afferent stimulation or is elicited by electrical stimulation of the midbrain reticular formation $[23,63]$. Theta activity is maximal during stare (e.g., at a mirror), search of a stimulus, pupillary dilation and inhaling odorous agents $[75,119]$. Grastyan has emphasised that theta is associated with the continuous alert behavior that occurs during task acquisition [62]. Similarly Adey [2] consistently found in cats that theta is maximal when cues for the visual discrimination appear, but the EEG becomes progressively desynchronised as the animal performs the discriminated response and approach. Recently Bennett and his colleagues [16] have emphasised the similarity in cats and in rats of the theta that was recorded in association with cues provided to assist in the acquisition of a DRL schedule of reinforcement. Such results 
have been widely reported in conjunction with the phasic suppression of theta to the immediate presentation of a novel stimulus for dogs $[175]$, cats $[2,15,26]$ and rats $[27,58,117]$. These two time dependent phenomena suggest a functional dissociation between noticing the presence of a stimulus and its identification.

Certainly in all subprimate animals theta trains are best correlated with the focussed attention that precedes and accompanies decision making or a sequence of learned behaviors wherein options and contingencies prevail. Where the decision turns out to be incorrect or there is orientation alone, theta patterns are qualitatively and quantitatively different $[2,55]$.

Herein lies the provocative implication of the hippocampus in both the perceptual selection and the decision making processes. One might ask if the persistence of a search strategy (right or wrong) that is facilitated by high androgen levels (see below) would be correlated with the difference of theta patterns, especially were reward important for the hippocampus to evaluate errors [47]. By contrast it is possible that theta might not change if it is related to the identification process of matching with central specifications without association with reinforcement. It would be worthwhile to exert some experimental effort on this question.

As a precautionary remark on the above discussion, it should be noted that there have been descriptions of two generators of theta rhythms in the hippocampus, the one sensitive to atropine, the other resistant $[17,165]$. Within the limits of their characterisation so far it would seem that the type of theta discussed here is sensitive to atropine (type II) and not correlated with voluntary locomotor activity.

Theta rhythms increase in extent proportional to the strength of electrical stimulation applied to the medial reticular formation, medial and lateral hypothalamus [3]. The tracts involved here are, respectively, the dorsal longitudinal fasiculus of Schültz and a noradrenergic component of the medial forebrain bundle (see discussion [167]). Segal and Bloom $[138,139,140]$ have reported that noradrenaline (NA) inhibited the spontaneous discharge of all the cells they recorded in the pyramidal cell layer of CA 1-3. These cells may also be inhibited by a loud tone. If the tone has become a conditioned stimulus for food the cells are excited and stimulation of the noradrenergic locus coeruleus potentiates this response.

The same cell population can therefore react in opposite ways to the same sensory input depending on the internal and external context. Internally NA has a potentiation effect. In reporting these results Segal and Bloom remain open for interpretations, but suggest "the locus coeruleus could maintain a screening function toward the hippocampus by reducing the excitatory responsiveness to non-significant stimuli and increasing the 'signal to noise ratio' of a response to significant stimuli." This possible filtering function is important to the functions that behavioral experiments (next section) attribute to mediation by the hippocampus.

In further support of this interpretation, lesions of the locus coeruleus that reduce hippocampal NA (70\%-[150], 96\%-[124]) render rats more distractible in a runway task to sandpaper on the floor and to a flashing light. This is opposite to the behavioral effect of hippocampal lesions in mammals [166], in birds [107] and the raising of androgen levels $[10,12]$ as seen in a runway task. In view of the apparent excitatory effect of ACTH on tonic stimulation it is not surprising that iontophoretic application of ACTH to pyramidal cells in the hippocampus antagonised the noradrenergic in- fluence [138]. Thus in the normal situation we in fact find that the secretion of ACTH can also be inhibited by noradrenergic neurons [142]. One might ask if gonadotropin secretion might also be so influenced?

\section{Behavioral Approaches}

Many studies have shown that hippocampal damage results in continued responding to a formerly positive cue when the operant schedule or the nature of the task has been changed or reversed $[47,71,81]$. Few if any of these studies can satisfactorily distinguish if the animal is incapable of inhibiting its motor response, having learned the association of stimulus with reward (which is also a description of the basic observation) or if the animal has problems with switching response, or attention, or selecting the salient properties of a new situation with new contingencies. This is because the most often used avoidance and operant conditioning tasks were not designed to distinguish between the perseveration of motor behavior and the persistence of the use of central sets of specifications controlling sensory selection.

In contrast some recent studies have combined the traditional paradigm with a more detailed analysis. They show firstly the importance of sensory cues to the execution of one of the roles of the hippocampus in these situations. Secondly the importance of the septo-hippocampal axis to the setting up of a strategy for the use of sensory cues is demonstrated. This is a theme that will recur again in the sections on hormonal influences.

As examples of the role of sensory cues one may take a passive avoidance and a brightness discrimination task. Animals with a hippocampal lesion have difficulty in withholding a learned approach response when that response instead of being reinforced is punished $[47,71,81]$. However this passive avoidance deficit disappears with the addition of cues associating external stimuli and goal box events [170]. Hippocampally damaged animals will perform a hrightness discrimination better under conditions of positive cue enhancement, but not under negative cue enhancement [65]. The suggestion is that by increasing the contrast between a stimulus with reinforcing contingencies and its background one can in part compensate for the function damaged by the lesion. The important point to be made is that the hippocampus has a role in the formation of a strategy for the selection of a sensory cue. The association of the cue with reinforcement may be reason for the selection. To further illustrate this point one can look at the impact on task performance of the deletion of sensory cues. If the salience of the deleted cue is high so should the effect on behavior be strong.

Donovick and his colleagues [45] presented both brightness and spatial cues to rats for the solution of a task in a 4-choice point runway. Animals with septal lesions made significantly fewer errors than controls. If the spatial cues were deleted, those with septal lesions still performed better. But if the brightness cues were deleted septally damaged animals were markedly impaired. It is unfortunate that spatial cues were used in this task as they may have particular significance for the rat species and for the hippocampalseptal axis $[112,113]$. However taking the two experiments together it would seem feasible that without a functioning septum rats do not divide their attention between cues, but "lock" on to one. If this alone is altered then their performance is disrupted. Controls, by contrast, have taken in information from both sources during training and can use both alone when the other is redundant. This interpretation is 
supported by an experiment where the number of choice points in the runway were varied [35]. The magnitude of impairment shown by the septally lesioned rats correlated with the number of strategies available for solution. At a descriptive level these results are surpisingly similar to some of the effects of steroid hormones that have been interpreted in terms of 'persistence'. These will be discussed in the following sections.

Mirror-image results have been reported for animals with widespread damage of the dorsal and ventral hippocampus [122]. This study used the situation where a rat pre-trained to a conditioned stimulus ' $a$ ' before being trained to the complex ' $a b$ ', does not evidence learning when tested with ' $b$ ' alone. ' $a$ ' and ' $b$ ' were a light and a tone. The blocking of the association of ' $a$ ' and ' $b$ ', as shown by the absence of conditioned responding, was shown to be attenuated by the hippocampal lesion. Lesioned animals responded to ' $b$ ' more than control animals.

Controls for learning deficits and sensory bias are discussed by both sets of authors, respectively. There is one conclusion and one speculation I wish to draw from these results. In these tasks animals with damage to one part or the other of the hippocampal-septal axis can register a relevant cue, but it is the nature of the selection that is differentially impaired. One may speculate that damage to the hippocampus impairs the ability to "lock" onto one cue. Redundant information is not filtered out. Damage to the septum impairs the ability to use redundant information. The animals "lock" on to the one salient cue. Both can result in the perseveration of responding to a compound stimulus.

There is another characteristic of hippocampal function highlighted by animals with hippocampal damage that points toward the phenomenon of persistence. They exhibit difficulty in shifting choices and this has been quantitatively related to their insensitivity to errors. This would be the process of incorrect matching. As a consequence such animals persist with strategies that in terms of maze running $[48,82]$ and discrimination problems $[48,72]$ may prove right or wrong. Indeed damage to the avian putative hippocampus also demonstrates the persistence of trained strategies (and by implication the maintenance of central specifications). Using the same tasks as are described below for testosterone-treated chicks $[107,108]$ birds with midline hyperstriatal and hippocampal damage were less distracted than other operated birds by black/white panels on a runway task and by pebbles in a food choice from an array of red and yellow grains. They were more tardy with respect to controls in changing from the trained food color preference despite shorter and longer periods of feeding on the non-preferred food color between tests [108]. A recent behavioral analysis of the reactions of Guinea fowl with hyperstriatal lesions to auditory signals suggests that there may be two mechanisms at work [110]. The one would restrict the availability of input for matching, the other would activate learned specifications for matching. This proposal is different from the one put forward above to explain hippocampal-septal function in mammals. But they may not be irreconcilable: both models are amenable to further investigation with careful control of the experience of sensory cues.

An examination of the search strategy problem has been carried further with rats [112]. In an arena containing 16 holes, food was located in four. Control rats rapidly learned not to visit empty holes (efficient) and developed a sequence oi food hole visits (pattern). As expected animals with hippocampal damage were inefficient and did not develop a pat- tern (this was expected as all rats had pre-test experience of finding food in all holes, the contingencies had changed for the test). Animals with hippocampal damage treated with the dopamine-receptor blocking agent haloperidol slightly improved their efficiency, but not their patterning, through a decrease of their species typical tendency to stay close to the walls. Thus they were able to find the central holes sooner. However control animals with the drug lost their patterning but not their efficiency. Thus the possibility exists that although they have a hippocampus (the spatial map for the four food holes is intact [113]) they have difficulty in using the acquired strategy for hole visiting. The effect of haloperidol could be on a polysensory area (e.g., striatum) connected to the limbic system. This drug also impairs the efficiency and ability to pair and to order sound stimuli in humans [57]. Furthermore corticosteroids are necessary for the maintenance of striatal dopamine levels [121]. Thus it would be of value to investigate the influence of the dopaminergic afferents from this area to the septo-hippocampal axis.

In the conditioning paradigm one would expect to see desynchronous activity coming to predominate in the hippocampus during the performance of the learned response. Stimulation of the median forebrain bundle elicits desynchrony in the hippocampus [3]. It would be interesting to see how damage to the dopaminergic component would influence the hippocampal rhythms.

I have tried to indicate how some physiological correlates for the registration of information and the application of a strategy have started to appear in experiments investigating hippocampal function. These correlates do not prove the hypotheses, but give rise to the hypotheses I have mentioned. These require further testing for improvement or refutation.

It would also be of interest to extend this work to the initial period of search by an animal for relevant information. For example the hippocampus is widely thought to be important for the orienting reaction. With Vinogradova's activating neurons as novelty detectors [159], and her inhibitory neurons as identity detectors, the hippocampus can perform match-mismatch operations evaluating new information. One such line for investigation concerns the inhibitory transmitter GABA. Although GABA is fairly widely distributed in the cerebral cortex and midbrain, levels are quite high in the hippocampus. Interestingly File [53] found the promotion of GABA reduces the number of head dips and the time spent head dipping when a rat explores a hole board (and vice versa with GABA antagonists). These are tantalising opportunities for correlating physiological change with attentive behavior. The following sections take up some of these in regard to the modulatory effects of hormones.

\section{ACTIVE SITES FOR HORMONES}

Some contributions of the hippocampal-septal substrate to attention and the associated measure of electrophysiology and behavior have been described. Because there are pertinent effects of hormones on the neurochemistry (e.g., steroid influence on amine levels) and on behavior (e.g., persistence/perseveration) that will be described, it is important to see that there are sites for the uptake of these hormones in the brain substrates under consideration. The physiological interaction of hormones with the hippocampalseptal axis is an important basis to establish before considering further what effects on behavior the two systems have in common. This review continues by briefly examining the 
connections between hormones from the adrenal-pituitary and gonadal axes and the hippocampus.

\section{Pituitary-Adrenal Hormones}

A consideration of corticosterone is important for its direct inhibitory influence on neural activity as well as providing feedback control to sites synthesising the releasing hormone for ACTH from the pituitary. Corticosterone concentrating regions are largely limbic-the hippocampus, lateral septum, amygdala, the pyriform, cingulate and entorhinal cortices [88]. Whereas the corticosterone content of these regions parallels plasma levels, that of the hypothalamus shows an inverse relationship [90]. The studies of McEwen and his colleagues $[99,100]$ and the autoradiographic work of Warembourg [163] have shown strong uptake of labelled corticosterone in the nuclei of pyramidal cells of CA 1 and CA 2 and in the dentate granule cells of the hippocampus (Fig. 2).

The unit activity recorded from these areas of the hippocampus is decreased after systemic injection of the hormone [116]. Low frequency electrical stimulation of CA 1 and CA 2 exerts an inhibitory influence on pituitary adrenal function [127]. The time course is complex. Early after stimulation corticosteroid levels may be raised [29] but fall later ([96], review [156]). Casady and Taylor [30] have recently tried to clarify the functional aspects here. They showed that electrical stimulation of the hippocampus in the morning significantly increases plasma corticosterone levels (reflecting ACTH release). In the afternoon, after an initial rise in hormone levels, stimulation gives rise to a temporary inhibition in the normal circadian rise of corticosterone levels. Unfortunately complimentary evidence is difficult to assemble from the literature on hippocampal lesions. In her review van Hartesveldt [156] found that methodological variability obscured unequivocal interpretation. Lesion of the hippocampal connections through the fornix and anterior cingulate seem to result in an elevated output of adrenocortical hormones in the rat $([18,20]$, caveat $[155]$ below). Steroid implants into the hippocampus can elevate basal levels of hormone [21]. Dexamethasone implants and adrenal removal lower corticosteroid concentrations [43]. Thus the hippocampus can form part of a positive feedback loop where a rise in hormone levels can facilitate the maintenance of such levels. In contrast it is reported that lateral septal lesions (and possible cingulate cortex) do not affect basal plasma corticosteroid levels but do prevent stress induced elevations [155].

There is less material regarding the specific binding of $\mathrm{ACTH}, \mathrm{ACTH}_{4-10}$ and similar peptides, although it is clear that lesions of the posterior thalamus, dorsal hippocampus and rostral septum upset the behavioral activities of these peptides [158]. Krieger [88] has shown that the amygdala and also the hypothalamus and preoptic area that possibly have separate effects on the orientation components of search and attention behavior, take up ACTH. More recently convincing evidence has been given [158] for preferential binding sites in the dorsal and fimbrial nuclei of the septum. Indeed septal lesions block the inhibitory effect of the related LVP on the extinction of a conditioned avoidance response [168].

The lateral septum and limbic cortex seem to mirror each other in that lesion of the former results in high pituitary ACTH levels, the latter in lower basal ACTH levels [155]. It has been suggested that the difference lies in the lateral septum controlling ACTH synthesis and the cingulate ACTH release [155]. It is not clear where the role of the medial septum lies, for the above study [155] reports only slight damage to this nucleus. There is a report [18] that lesion of the medial nucleus, like the cingulate, elevates output of adrenocortical hormones. However from the point of view of potential modulation by hormones of the limbic behavioral functions these may be fine points if there is direct passage from the pituitary to the brain ([98], see below).

Clearly both the septal and the amygdaloid sites are in a good position to modulate hippocampal activity. It may also be argued that the posterior thalamus is in a good position. It is here in the parafasicular nucleus that vasopressin has been found to have some behavioral effects $[148,169]$. The next two sections on the interactions of the pituitary adrenal and hippocampal axes discuss the behavioral implications further.

It is important to note that for many of the present studies these central effects may not represent the results of systemic uptake of ACTH, which results in "insignificant" labelling [88]. Transport to other parts of the brain may occur by way of the cerebrospinal fluid. A vascular route has been indicated for pituitary-hypothalamic transport [98]. There may also be one or more unknown sources within the central nervous system. It has recently been shown [115] that the rat brain amygdaloid nucleus will, in culture, secrete ACTH. Although some studies have shown behavioral effects of peripheral source of ACTH (e.g. [33,73]), it is not yet clear which ACTH-mediated effects on attention behavior come from a pituitary and which from a more central source.

\section{Gonadal Steroid Hormones}

Sites for uptake of labelled gonadal steroids are now considered because of their influence on behavior that will be elaborated later and their influence on brain amine content and tumover. Thus in rats and mice manipulations of the pituitary gonadal axis alter NA concentrations and turnover in the hypothalamus $[32,44]$. Fluorescence studies suggest effects on catacholamines in structures as diverse as the preoptic and caudate nuclei [93]. NA levels in the lateral septum increase between estrus and metestrus in the rat. The DA levels in this nucleus are highest in diestrus [34]. In turkeys increases in brain synthesis of DA and 5-HT have been correlated with varying degrees of gonadal regression [49].

In discussing sites for steroid uptake here, the wellknown diencephalic sites and others whose function has been explicitly linked to the control of reproductive behavior or to motor control (song) are excluded. Between testosterone and estrogen there is little evidence showing differential uptake in different areas that have not been shown to be involved in reproductive control $[97,174]$, although a thorough study for testosterone over many brain regions is missing for mammals. The higher concentrations of testosterone in the ventral thalamus and torus semicircularis of amphibia are two of the few examples [79]. With the above exclusions there remain in mammals sites in the lateral septum, ventral hippocampus and entorhinal cortex and in birds there is labelling in the lateral septum and stronger labelling in the dorsal rather than the ventral hippocampus $[96,174]$. (There has been a suggestion of analogous roles between the avian dorsal and mammalian ventral hippocampus $[107,108]$.) However one study of the lizard reports an absence of labelling in the hippocampus [97], although labelling was seen in the lateral septum. It is fair to 
A
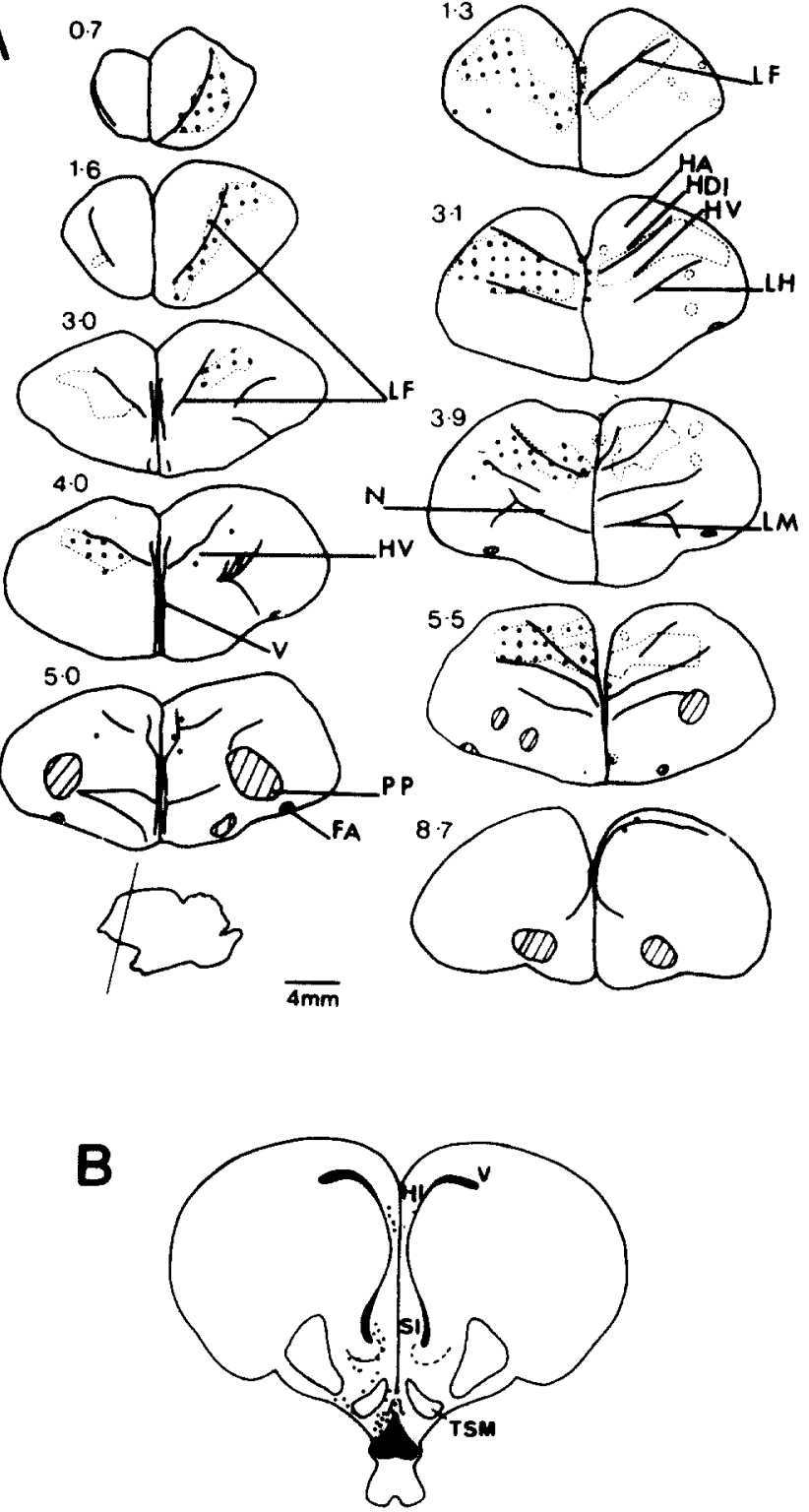

C

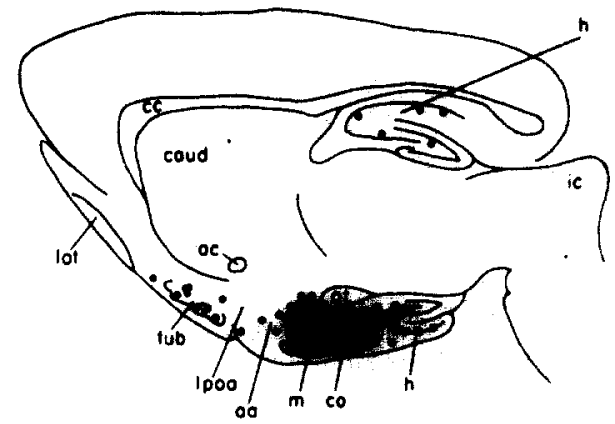

D

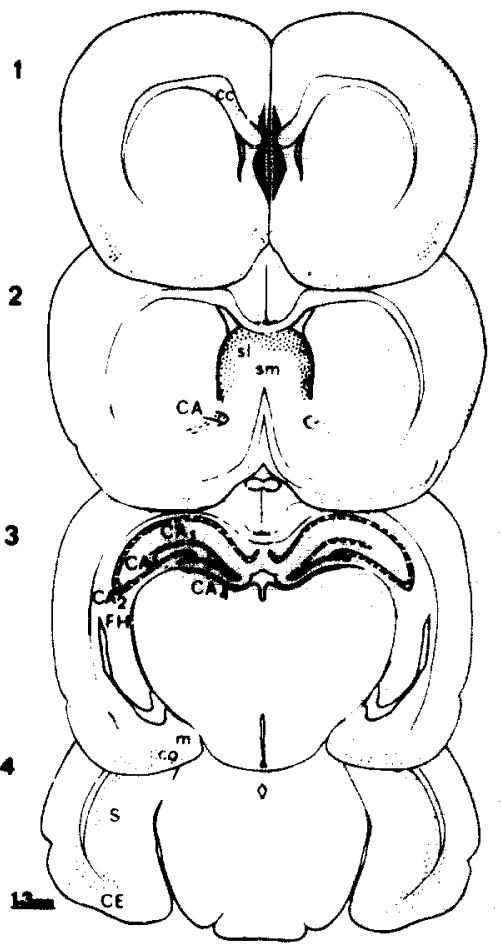

FIG. 2. (A) Camera lucida drawings of transverse sections of the chicken forebrain showing uptake of progesterone (left) and testosterone (right) in different layers of the striatum (after Wood-Gush et al. [174]). (B) A drawing of a transverse section of the dove brain showing uptake of estrogen in the hippocampus and septum (after Matinez-Vargas et al. [96]). (C) A drawing in the lateral plane of a longitudinal section of the rat brain showing estrogen uptake in the hippocampus and amygdala (after Morrell et al. [105]). (D) Drawings of rat brain transverse sections showing corticosterone uptake, particularly in the entorhinal cortex, hippocampus and septum (after Warembourg [162]). Abbreviations: aa-anterior amygdala ac-anterior commissure $\mathrm{CA}$-cell area, hippocampus caud-caudate nucleus cc-corpus callosum $\mathrm{CE}-\mathrm{entorhinal}$ cortex $\mathrm{Co}$-cortical nucleus, amygdala FH-fimbria hippocampi h, HI-hippocampus HA-hyperstriatum accessorium HDI-hyperstriatum dorsale and $\mathrm{n}$. intercalatus hyperstriaticus HV-Hyperstriatum ventrale ic-inferior colliculus LF-lamina frontalis superior LH-lamina hyperstriaticus LM-lamina medullaris dorsalis lot-lateral olfactory tract lpoa-lateral preoptic area m-medial nucleus, amygdala N-neostriatum PP-paleostriatum primitivum S-subiculum S1/m-septum lateral/medial TSM-tractus septomesencephalicus tubolfactory tubercle V-ventricle. 
say that investigations of estradiol uptake in the brains of mice and monkeys have emphasised the amygdala (medial and basal accessory nuclei), septum (dorsolateral and medial) and the nucleus stria terminalis ([78,162], Fig. 2).

So far lesion studies have not proved very illuminating. The sex differences of rats on the acquisition of an active avoidance task or extinction of a passive avoidance were not altered by gonadectomy [14]. Gonadectomy tended to attenuate hyperemotionality in both sexes and induced hypoactivity in females following septal lesion. These are not tasks designed to show up anything but the grossest of deficits in cognitive function. What might be significant is that septal lesions result in the testosterone levels of gerbils doubling [89]. This suggests that the feedback control of secretion from septal uptake is impaired. It is unlikely that such a rise would be without cognitive effect. Alas this study only reported on open field behavior which does not accurately reflect exploratory tendencies.

In the midbrain the intercollicularis nucleus and the dorso-lateral thalamus, both of which have multiple functions, also stand out as binding gonadal hormones. There are neurophysiological results [126] showing that estradiol changes the responsiveness of brain stem neurons to somatosensory input, but extensive treatment of results outside the forebrain is beyond the scope of this article. However because of the special connections of the locus coeruleus to the hippocampus it is interesting to note that estrogen (and progesterone) uptake has been recorded from this noradrenergic nucleus [146]. This could be important from the "screening" function that Segal postulated for the locus coeruleus (above, [138-140]).

Thus it is clear that in a discussion of the neural structures likely to be involved in attention processes limbic structures will predominate. In the future it is to be hoped that more evidence will accumulate to define the roles that the limbic thalamus and amygdala are certain to have on attention.

Finally in this section it should be warned that interpretation of specific hormonal manipulations must take into account the growing evidence for interactions between the gonadal and pituitary axes. Peripherally it has been found that the clinical treatment of men with cortisol can suppress plasma testosterone levels and thus the amount of hormone available for central binding sites, by flattening the normal nocturnal rise [43]. Centrally the ventricular injection of $\mathrm{ACTH}_{1-24}$ is associated with increased testosterone levels (also progesterone and corticosterone). However this effect might be limited to central stimulation. Cushing's disease is associated with lower plasma testosterone levels [94]. The application of ACTH to adrenal cells taken from a patient with Cushing's syndrome promoted the release of testosterone from these cells. These studies, cited by Doerr and Pirke [43], show that a closer study of the facilitatory/inhibitory influences over lower/higher concentrations of pituitary adrenal hormones on circulating levels of gonadal steroids is required.

In addition the feedback of gonadal steroids on the pituitary adrenal axis is implied by studies of estrogenic influences. On the one hand ovariectomy disrupts the timing of corticotropin releasing hormone secretion, and on the other hand when estrogens are implanted in the arcuate or lateral mammillary nuclei, plasma corticosteroid levels tend to rise [68].

At this stage it is difficult to assess the potential effect of these influences on behavior. One study [85] reported that an analysis of cortisol levels during the menstrual cycle pro- vided no conclusive correlations with female behavior. Nonetheless experimental design should note that serum corticosteroid levels are lower in women during the follicular phase of the menstrual cycle than in the luteal [137]. (MSH might be responsible for increasing cortisol levels in the corpus luteum phase, [128].)

Fortunately some recent studies acknowledge this problem. It is encouraging that the levels of $\mathrm{MSH}_{4-10}$ used by Veith and others [157] produced no significant alterations in the levels of $17-\beta$-estradiol and cortisol (LH and FSH) in their subjects. Future experimentation should try to elucidate the details of these potential interactions and it would be profitable to note more often the influence of the manipulations investigated in the one system on the functions of the other.

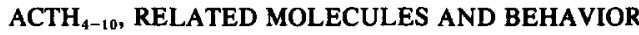

There is increasing support for the idea that at brain sites that concentrate hormones, these molecules may act as neuro-modulators [103]. One of the manifestations of such action may be as a result of changes of thresholds of excitability. Such possibilities fit well with some of the models that are put forward to interpret physiological influences on behavior. I will now consider with regard to the peptide hormones what some of these influences are on attention related behavior.

Leshner [92] proposed that the hormonal state of an animal contributes to a determination of whether, in what way and how intensely it reacts to environmental stimulation. Of the several likely functions of an hormonal response to environmental stimulation, one may be to modify continuing and future behavior in similar situations. A baseline state of the hormone "presets or prepares" both sensory receptors and central processing mechanisms. The central processes affected may be various, but if the way stimuli are perceived is under the control of this state, it will then set limits for reaction.

A number of experimental studies suggest that the release of pituitary adrenal hormones and ACTH not only may accompany behavioral changes (e.g., fear response) but may affect the degree and nature of the behavioral change. Thus ACTH (and the similarly acting MSH fragments) enhance the retention of learned responses and the acquisition of avoidance and approach responses in intact and adrenalectomized rats $[18,19,40,41,168,169]$.

De Wied [40] postulates a plausible explanation for ACTH increasing the adaptive behavior of rats in shock avoidance situations and in delaying the extinction of food and sexually motivated behavior is for it to cause an increase in "motivation". But the design and analysis of these tasks has not usually addressed itself to questions about the ability to attend to relevant cues (cf. [129], below). We have seen in the discussion of the effect of hippocampal lesions on behavior that the presence of rewarding contingencies can be important. Where such contingencies are emphasised (e.g., active avoidance) one would expect motivation to strongly influence attention and learning. Thus these tasks are less useful if one is attempting to distinguish unequivocal attentional or motivational mechanisms.

The pituitary adrenal system may not be essential for acquisition but it may modulate such processes. More importantly it may be required for the retention or suppression of behavior. The result of administration of pituitary peptides such as $\mathrm{ACTH}_{4-10}$ and vasopressin is one of clear improve- 
ment of long term processes. Brattleboro' rats that are deficient [22] in vasopressin learn a passive or active avoidance according to tests taken immediately following acquisition, but not if tested later. Administration of vasopressin brings about an improvement of memory. Clear effects on memory are not the subject of this article. However in passing one may note that attention to and recognition of a relevant stimulus requires the retrieval of a learned parameter. Attention, recognition and memory may be successive processes on a continuum. The close relationship of these processes is supported by recent work from the same group where they propose that ACTH activates reticulo-limbic circuits facilitating retrieval from memory and thus promotes attention or motivation [123].

The vasopressin molecule may be split into $\beta$ endorphin (and ACTH). This has an effect on anxiety and therefore reasonably on the degree to which "motivational" processes (short and long term) are shown [103]. I shall continue to examine what evidence there may be that the other fragment $\left(\mathrm{ACTH}_{4-10}\right.$ inc.) is involved in attention processes.

For many of the experimental situations in which the active $\mathrm{ACTH}_{4-10}$ (also $\mathrm{ACTH}_{4-7}, \mathrm{ACTH}_{1-24}, \beta \mathrm{LPH}_{61-76}$, aMSH) has been found to affect task performance it is either unclear if the effect is on an attentional or memory and storage mechanism. However $\mathrm{ACTH}_{4-10}$ can improve the efficiency of search behavior. Earlier I have emphasised that one of the important characteristics of a selective attention process is the ability to inhibit irrelevant influences. Rats are better able to find a water dish in a new position on one of four elevated tables if the peptide is administered between the rat being shown the dish in position and the test trial [73]. By comparison with control rats responses are suppressed toward irrelevant tables.

Some earlier studies also provide good reason to look for an effect on attention that is in play during search and acquisition processes. Visually deficient rats (albino) acquire a reversal slower than hooded rats [130]. MSH injection assists such disadvantaged rats as it also does when they are disadvantaged by light conditions [131]. These investigators concluded that MSH leads to an increased awareness of the environment. This supported one of their previous conclusions that improved passive avoidance learning after injection may rely more on attention to contingencies than motivation sensitivity [129].

Recently there have been a number of reports for rats [13, $31,131]$ and men $[54,102,132,133]$ of a modulatory effect of ACTH/MSH ${ }_{4-10}$ on attention mechanisms.

In the first series of reports with rats, the animals were trained on a black and white discrimination in a Thomson Bryant box. With subcutaneous injection $5 \mathrm{~min}$ before original learning they recorded no influences on acquisition [131]. However acquisition of a reversal was enhanced in male rats through a decrease of the proportion of responses to the previously positive stimulus [31]. By contrast females did not show enhanced reversal acquisition because of an enhanced position orientation. The improvement of male performance and the lack of an effect on females has also been recorded for acquisition, reversal and extradimensional shifts in a discrimination [13]. An interaction of sex in the persistence of attention directed to visual cues or space occurs again in the discussion of sex steroid effects on attention.

It is tempting to speculate and compare the enhancement of reversal learning with the performance of decorticate rats [145]. After task reversal such rats make fewer responses to the formerly rewarded stimulus than intact animals. This analogy suggests, at the least, that certain species-typical probabilities of selection of a stimulus are prevented when there is a task in hand to be resolved. Champney's result [31] presents $\mathrm{ACTH}_{4-10}$ as one of the possible mediators for this inhibition when such is adaptive.

Interpretation of reversal studies are particularly prone to methodological criticism. One problem is that with overlearning the ease of reversal increases [147]. Thus although one cannot neglect this often used measure here, the use of other attention-oriented tasks will be given prominence in this discussion.

Let us consider a study that implicates $\mathrm{ACTH}_{410}$ in attention processes and then consider one or two others that lead toward an understanding of in what way ACTH $_{4 \cdots 16}$ might affect attention. Gaillard and Sanders [54] ran a selfpaced serial reaction time task for 30 minutes. Normal performance of the human subjects showed a real improvement in reaction time that was in part counteracted by increased intervals attributable to fatigue and lapses of attention. It was precisely by shortening these lapses that treatment with $\mathrm{ACTH}_{4-10}$ improved the attention and thus the performance of the subjects.

Beckwith [13] applied an extra-dimensional shift to a visual discrimination with albino rats. He found that although the terminal functions of the learning curves were similar for MSH-injected and control groups, the presolution period of the changed dimension was shortened for aMSH and $\mathrm{ACTH}_{4-161}$ groups. This is precisely one of the rules postulated for an attention process in the introduction and again suggests that alternative strategies under some conditions can be inhibited.

As yet these results with rats should be treated cautiously. The results are on the border of statistical significance. There is still some uncertainty as to the physiological nature of the doses and the duration of their effects. Nonetheless it is encouraging that there are suggestions in man of faster intradimensional shifts in a Wisconsin test apparatus $[132,133]$.

In man there are other improvements of both visual memory and attention after the injection of $\mathrm{ACTH}_{4-10}$ [133]. Such effects include the reduction of errors on a Benton visual retention test. Perhaps more pertinently there is a reduction of errors of omission rather than commission on a continuous performance task (spot the ' $x$ ' during a rapid presentation of letters on a screen) following subcutaneous injection of $\mathrm{ACTH}_{4-111}$ [102]. As before this suggests an increased directed concentration and attention to the task in hand. It would be of interest to know if this effect depends on the sex of the subject, as with the rats discussed above and with humans on other tasks [157].

One reason for considering an interaction with sex comes from consideration of the embedded figures task. Such a task requires the opposite of persistence (in terms of rules for selection), that is the successive change of central specifications for matching as the subject attempts to extract simple forms from complex geometric figures. Poor performance has been attributed to a perceptual approach where subjects adhere to the structure of the presented field. Improved performance has been attributed to a conceptual approach of "hypothesis development," that is to say grouping blocks of the diagram together [66]. The requirements of this task are not facilitated by high levels of testosterone. Women are said to perform similarly to men with high levels of testosterone but consistently worse than the average of most male sam- 
ples $[4,171,172]$. A slight improvement has been noted on the embedded figures task after infusion with $\mathrm{ACTH}_{4-10}$. Perhaps continuing and more direct tests of the ability to categorise should be introduced to subjects with ACTH controlled.

Some investigations have started in this direction. The responses given by subjects during tasks that concentrated on the dimensional aspects of a discrimination showed that the method employed for solution varied between $\mathrm{ACTH}_{4-10}$ and control solution treatment. Hormone treatment facilitated responding to the dimensional aspects of the task [132]. Subjects have also been required to align a pole vertically inside a frame against a distracting background and to detect dots of differing sizes at different degrees of luminance. Again with these studies questions arise over the criteria used to demonstrate significant effects, but the results do show a trend towards $\mathrm{ACTH}_{4-10}$ impairing the reception of simple stimuli whilst the recognition (and the decisions that follow, i.e., registration) is facilitated. Performance against background distraction is enhanced.

If these results are repeatable they are astonishingly similar to the reciprocal effects on detection and recognition thresholds that Henkin [68] has demonstrated for carbohydrate active steroids (described below) and to the lack of distraction from the background shown by testosteroneinjected chicks (last section). These characteristics of recognition thresholds and distractibility are clearly those that are important for the registration of significant stimuli and the process of selective attention. The most important attribute of this must be the discrimination of relevance from irrelevance, which was clearly improved by the administration of $\mathrm{ACTH}_{4-10}$ [135].

\section{EFFECTS OF CARBOHYDRATE ACTIVE STEROIDS}

Striking results have been reported by Henkin [68] on the sensory capabilities of patients with adrenocortical insufficiency and the changes wrought by treatment with carbohydrate active steroids (CAS-e.g., prednisalone). Effects were found with the olfactory, gustatory, auditory and visual modalities, but for the sake of brevity only the auditory modality will be considered here.

The normal mean lower limit of the human auditory frequency response is $50 \mathrm{~Hz}$ and the upper limit is about 15,500 Hz. The sensitive frequencies for detection are $1-4 \mathrm{kHz}$. For his patients detection thresholds proved variable and their acuity extended over a further $31 / 2 \mathrm{KHz}$, particularly in the sensitive range. Doses of $20 \mathrm{mg}$ prednisalone restored the threshold after two days of treatment. Similar results emerged from investigation of gustatory responses. Patients showed detection thresholds far lower but recognition thresholds higher than normal patients. Again prednisalone (not related sodium/potassium active steroids) restored the threshold to normal.

The auditory investigation went further to suggest that patients showed an impairment of the "recognition and/or integration of information." A list of 50 phonetically balanced words were presented at $40 \mathrm{~dB}$ and $60 \mathrm{~dB}$ above the patients' threshold. Frequencies over $500 \mathrm{~Hz}$ were filtered out (low pass filtered speech). At $40 \mathrm{~dB} 60 \%$ of untreated patients recognised the words in the balanced list and $89 \%$ at $60 \mathrm{~dB}$; whereas $89 \%$ of normal and treated patients showed recognition at $40 \mathrm{~dB}$ and $96 \%$ at $60 \mathrm{~dB}$. Untreated patients also proved deficient in their abilities to localise sound stimuli and to judge loudness, suggesting hormonal influ- ences beyond the 'boundaries' of attention to sensory processing capabilities.

It appears that not only primary sensory abilities may be modified by the internal hormonal balance but also the way in which such information is treated and may become registered for future use by the individual. This echoes the effects described above [135] of $\mathrm{ACTH}_{4-10}$ on detection and discrimination. However it should also be remembered that whatever the reason for the secretion of a particular hormone it is likely to affect much of the brain and not just the loci considered in this article, where the hormone may be bound.

For example there is a correlation between the frequency of the EEG alpha rhythms and adrenal cortical function [106] with low levels depressing the dominant frequency [51] as with the theta rhythm of the hippocampus. This could be the result of a common fundamental effect on neurons rather than nuclear or cytosol binding. Thus Henkin [68] reported that multi-synaptic conduction time can increase by $20 \mathrm{msec}$ after the removal of CAS. If the conduction times change, tendencies towards desynchrony could be promoted in the influenced areas giving rise to the EEGs recorded. Such an effect might be one superimposed on the areas where specific binding has been reported (e.g., hippocampus [100]).

The selective increase of high voltage activity in the 4-9 $\mathrm{Hz}$ band shortly following MSH injection [134] fits seductively into such a scheme of attention mechanisms because of the likelihood of the rhythm being hippocampal in origin. But the similarities of the effects of peptide and steroid hormones can dangerously obscure their differences. These important effects of ACTH on limbic electrical activity $[101,134]$ are pursued in the following section.

PHYSIOLOGICAL INTERACTIONS OF PITUITARY-ADRENAL HORMONES WITH THE HIPPOCAMPUS

Evidence has been elaborated for the uptake of pituitary adrenal hormones by the hippocampus. This section proceeds from how the hippocampus can influence hormone levels to how the hormone-hippocampal relationship might affect behavior. The limbic system needs to be intact for some of the behavioral actions of the neuropeptides and steroids to be seen $[20,40]$. For example lesion of the antero-dorsal hippocampus prevents the inhibitory effects of vasopressin and $\mathrm{ACTH}_{4-10}$ on the extinction of a one-way avoidance test. For behavioral control it is probably important that there is a feedback relationship between the hippocampus and adrenal and pituitary hormones. The functional importance may be in Kawakami's words [77] perhaps to "tune" the animals' ability to respond to the same stimuli in different ways (i.e., in different hormonal environments). This recalls Leshner's model in which steroid hormones "set" an animal's baseline state with respect to its treatment of incoming information.

The means by which the inhibitory characteristics of the hippocampus $[15,114]$ are realised may be through the 5-HT system. The 5-HT content of the hippocampus, amygdala and frontal cortex varies with plasma corticosterone levels (see [74] for review on hippocampal-frontal cortex interactions on learning). 5-HT release seems to be involved in the inhibition of some behavioral tendencies. Blocking 5-HT synthesis with PCPA facilitates the appearance of some behavioral characteristics that are often seen after hippocampal lesions [111].

Let us take a specific example of this characteristic [120]. 
On a one trial passive avoidance the administration of $\mathrm{CO}_{2}$ after the trial can induce amnesia and inhibition of the 5-HT rise in the hippocampus that is normally associated with acquisition. If lysine vasopressin is given to the rats before the task then the normally observed rise of 5-HT in the hippocampus is restored.

Further investigations are required to illuminate the mechanisms in detail. But this example does serve to illustrate a way for the interactions of the limbic system and pituitary adrenal hormones to affect the balance of biogenic amines and thus affect the processing of information. The weakness yet lies in whether one is describing the phenomena of attention or learning which lie at different stages along the continuum discussed in the previous section on ACTH.

On moving to consider some influences of ACTH one can approach phenomena that are closer to that of an attention process. The dominant frequency of hippocampal theta activity that is recorded from dogs during the prestimulation 'facing' period of a conditioned food reinforced operant response shows a downward shift following the administration of $\mathrm{ACTH}_{4-10}$ [152]. No discernible effect was observed on the conditioned behavior itself. However when theta rhythms are elicited by electrical stimulation of the reticular formation of rats, then the presence of $\mathrm{ACTH}_{4-10}$ increases the components in the 7.5-9.0 Hz band ([153], Fig. 3). This has also been well demonstrated following injection of vasopressin into Brattleboro rats ([154], Fig. 3).

Evidence for humans has been provided by a study from Miller and his colleagues [101]. Subjects participated in a disjunctive reaction time task with warning signals. One warning signal preceded a signal to respond, another preceded a signal requiring no response. To both signals control subjects habituated their initial arousal response (alpha block) as measured by desyncrhonization of the EEG. $\mathrm{ACTH}_{4-10}$ treated subjects only habituated to the "no response' signal. They showed an EEG shift towards higher frequencies (periods of $7-12 \mathrm{~Hz}$, for example) in the interval between a response and the next warning signal. This is clearly an improvement in the field of vigilance and attention (cf Fig. 1). Similar changes are observed by increasing stimulus intensity. It appears that $\mathrm{ACTH}_{4-10}$ increases the excitability of the theta generating system. This could be mediated by decreasing the turnover of 5-HT.

These results throw some light on conclusions from behavioral investigations. De Wied [40] has suggested that ACTH increases the motivational significance of stimuli. Alone and brief this statement remains unclear. But if one looks closer into such a mechanism, it may be possible to speak in terms of ACTH increasing the contrast with which a stimulus stands out from the background by reason of a reinforcement history (potential motivational influence). Thus the stimulus has 'significance'. This is precisely the effect that has been shown with the increase of components in the 7.5-9.0 Hz theta wave band.

Further support comes from measurements of the human

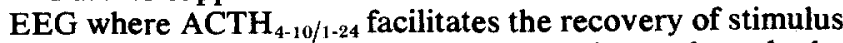
specific arousal patterns [102]. In a more thorough study the average evoked responses (AER) to four intensities of light have been recorded from patients with adrenocortical insufficiency [28]. The amplitude of the recordings was small and of short latency. If such patients were treated with ACTH alone the amplitude was depressed (a reducing effect on the P 100 wave). But if the patients were treated with CAS the amplitude increased. The interesting development for the
RAT HO 6

mean $\%$ of power/c's \pm SEM
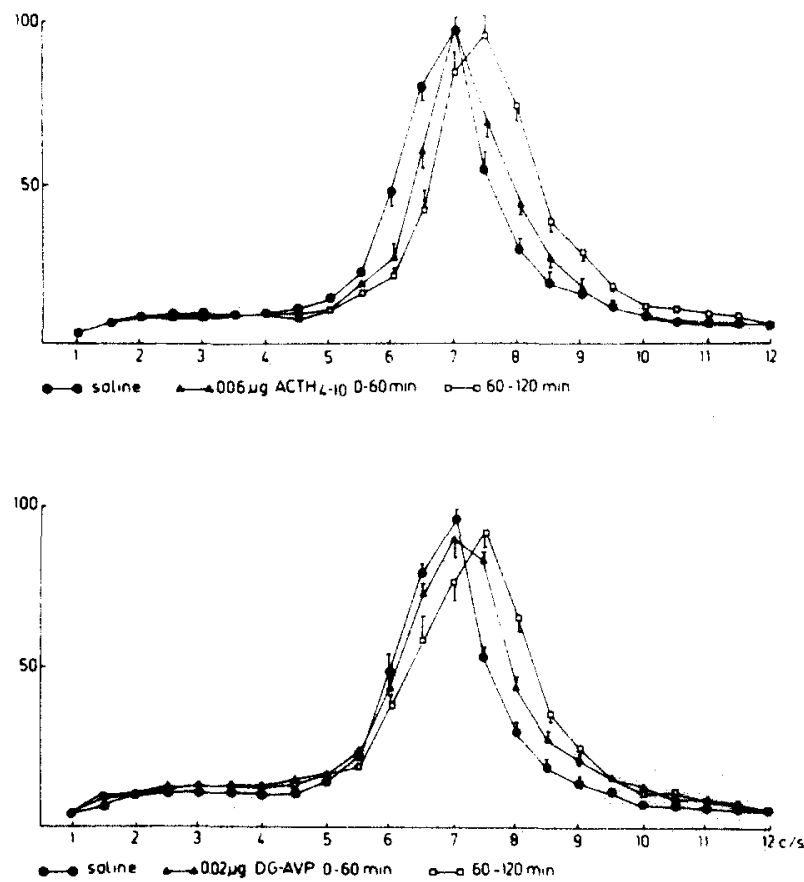

FIG. 3. This diagram shows the composition of theta activity in homozygous Brattleboro rats (HO-DI) 0-60 and 60-120 min following intraventricular injection of desglycinamide-arginine-vasopressin (DG-AVP) or $\mathrm{ACTH}_{4-10}$. An increase in peak frequency of 0.7 and $0.8 \mathrm{c} / \mathrm{sec}$, respectively, is shown (after Urban and de Wied [153]).

present discussion is that prolonged stimulus presentation with $\mathrm{ACTH}_{1-10 / 1-24}$ diminished stimulus habituation [50]. This again suggests an excitatory action for the active peptide $\left(\mathrm{ACTH}_{4-10}\right)$ for neural processes of a tonic, ongoing nature (e.g., stimulus is examined, theta driven, then both AER and behavior habituate) but inhibitory where processes are phasic (e.g., orient to novelty, theta depressed and P 100 of AER is depressed).

Lastly in this section I will consider a separate approach to the interpretation of the interaction of EEG rhythms and hormones. The situation where a learned behavior pattern is extinguished theoretically requires the animal to direct its attention to new salient features and/or to change its set of central specifications for the previous task. Thus combining the use of this task and deep recording the question of the hippocampus as a biological base in attention is more closely approached than is possible from the results of EEG records from the skull surface.

Gray and his colleagues (e.g. [40]) have shown that septal driving of hippocampal activity with a frequency of $7.7 \mathrm{~Hz}$ decreases resistance of rats to extinction of a reinforced runway response $[59,60]$. Further corticosterone, in a dose that facilitates the extinction of a runway response, selectively alters the driving threshold for the evocation of a theta rhythm to about $7 \mathrm{~Hz}$ [61]. It is clear that the requirements of the task are best met by a specific band of theta activity and that hormones facilitate the process by which the hippocampus fires in this mode. The presence of testosterone, naturally or by injection, to castrated or female rats also appears important for a $7.7 \mathrm{~Hz}$ rhythm [61]. 
I would suggest that this contributes a degree of support for the idea that these hormones act through their modulation on the hippocampal theta rhythm to increase 'significance' or contrast of the key stimuli against their background. It does not permit us to say that this is the precise mechanism but that this is the effect produced by the hormones.

Gray has provided further evidence from his examination of the partial reinforcement effect [61]. The increased resistance to extinction found after a partial reinforcement task (compared to after a continuous reinforcement task) may be due to the animal attending to more varied aspects of its environment during training [147]. If testosterone can also produce the effect of heightening the contrast of key stimuli [4,5], that would result in persistent attention to a limited number of stimuli, then one would expect to find a strong effect on partial reinforcement tasks in animals with higher levels of this hormone. Indeed Gray found that testosterone treatment of his rats decreased their resistance to extinction following training on a partially reinforced task. This line of interpretation of the effects of testosterone on characteristics of an attention process is taken up in the following section.

\section{CIRCULATING GONADAL STEROIDS AND PERSISTENCE}

A consideration of the influences of testosterone on attention and search behavior largely comes out of a series of studies on birds by Andrew and his colleagues and on men by Broverman and his colleagues. Work with female sex hormones consists for the most part of early work on menstrual cycle correlates, the cognitive aspects of which have been recently investigated by Sandman and his colleagues. This work on sex differences is suggestive of differential roles of steroid hormone levels on attention-related processes.

\section{Testosterone}

The studies of testosterone are interesting for their effect on the 'rules' for an attention process. This effect is interpreted as the persistence of the matching of the registered central specifications with sensory input that results in the more rigid control of behavior (cf. start of introduction).

The injection of testosterone to male chicks in their first two weeks of life increases the persistence of search for a particular type of food and for search in a particular place depending on the context of the task [7]. Such persistence includes a decreased distractibility by irrelevant stimuli and sustained gaze on a localised stimulus. Thus, for example, chicks trained to peck at red grains of food and to prefer these to yellow grains were presented with a pebbleencrusted floor where both foods were available. Food deprived chicks that had been injected with testosterone showed longer runs of feeding pecks on red food than their oil-injected counterparts [4]. On a plain floor the runs of red pecks are shorter for, without the distracting pebble stimuli, the testosterone injected birds sustain their search in a particular place for longer than controls. Thus yellow grains are more often taken.

What may be happening is elaborated by Rogers' [125] description of the moment when the chicks move. "Control males on the pebble floor showed switches in their search specifications, because of their acceptance of non-preferred food (NP) before a move that generated a strategy in which NP food was taken over the next few moves; i.e., they were now searching for NP food in preference to $P$ food, since they took NP food even when given a choice of both colors in the new area. Such switches in search specifications were also seen in controls on the plain floor, although less often, but they were not seen in testosterone-treated birds".

Andrew [5,6] suggests that after the administration of testosterone the central specifications used in the recognition of a particular type of stimulus are likely to remain more persistently in use, once activated. Testosterone opposes tendencies to change the rules controlling attention and guiding selection. He argues that the acceptance of yellow grains (e.g., on a plain floor) by chicks with a red preference may be reasonably interpreted as a relaxation of the criteria of match between specifications for preferred food and the characteristics of grains that will evoke pecks. It should be remembered that red and yellow grains are similar in size, texture and shape. This is a more parsimonious explanation than describing a change of specifications that would require further assumptions to describe a return to $P$ food. One of the appealing aspects of this analysis is that the concepts have much in common with Treisman's [149] description and review of evidence for the selection of the test/target during selective attention.

Rogers [125] provides supporting evidence for Andrew's analysis. "On the pebble floor pecks delivered by broadening the criteria of match were most likely to be delivered to pebbles, which were the same color as $\mathrm{P}$ food. Color is known to be one of the most pertinent visual cues for chickens [37]. Pebble pecks were found to occur significantly more often just before a move than just after a move" (Fig. 4).

The above analysis is supported by ethological observations [8-11]. If chicks have been trained to run to the end of a runway for a food reward are presented with black and white panels on the sides of the runway, they will show an increased latency to reach the food. Testosterone-injected chicks are less distracted by this irrelevant stimulus. During an extinction of this runway response testosterone-injected chicks showed a fixated gaze at the walls by the dish for longer than controls (longer periods of fixation and fewer head moves during scanning were also found in an open field). These chicks did not look up from the runway as often as controls.

Using the runway with mice, Archer [12] has demonstrated similar effects of circulating androgens for mammals. He found, using similar visual cues as were used in the chick study that injection of testosterone into castrated male mice increased persistence and that intact male mice resembled them more than control-injected castrates. As has been found with chicks in the feeding situation [4], the behavior of female mice resembled none of the male groups.

Results obtained from adult birds also confirm the physiological nature of these findings [125]. Antiandrogen treatment of adult male chickens decreased their persistence on a food choice task. Castrated males were less persistent until injected with testosterone. In another situation there seems to be evidence for a similar effect on the rules developed during search behavior. Whilst learning a match to sample test in a T-maze quail exhibited longer sequences of responding (in terms of a particular hypothesis for solution-right or wrong) than did castrated birds [109]. This effect was more marked than that of the experience that some birds had had learning a similar but simple discrimination earlier in the $\mathrm{T}$-maze, on their pattern of alley visits. This is further support for an interpretation that once activated the central 
TABLE 1

THIS TABLE SHOWS THE MEDIAN VALUES OF THE SCORES OF FEEDING PECKS (PERCENTAGE AND RUNS OF PECKS) TAKEN FROM THE MEANS FOR INDIVIDUAL CONTROL AND TESTOSTERONE-INJECTED 12 DAY OLD CHICKS ON A FOOD ARRAY OF RED (PREFERRED, P), YELLOW (NON-PREFERRED, NP) AND PEBBLES

\begin{tabular}{clccc}
\hline $\begin{array}{c}\text { Scores for First } \\
\text { 100 Pecks }\end{array}$ & $\begin{array}{c}\text { Untreated } \\
\text { Females }\end{array}$ & $\begin{array}{c}\text { Untreated } \\
\text { Males }\end{array}$ & $\begin{array}{c}\text { Testosterone } \\
\text { Treated Males }\end{array}$ \\
\hline \multirow{2}{*}{ Percentage taken: } & P food & 81.5 & 84.0 & 97.5 \\
& NP food & 14.5 & 6.0 & 0.0 \\
& Pebbles & 3.5 & 6.0 & 2.0 \\
Mean Run Length: P food & 9.8 & 10.4 & 36.7 \\
& NP food & 2.2 & 1.5 & 0.0 \\
Longest Run: & Pebbles & 1.3 & 1.1 & 1.0 \\
& P food & 24.0 & 33.5 & 69.5 \\
& NP food & 3.5 & 2.0 & 0.0 \\
& Pebbles & 2.0 & 2.0 & 1.5 \\
\hline
\end{tabular}

Longest run on $\mathbf{P}$ food; untreated male $>$ untreated female, $0.025<p>0.05$.

All other feeding scores; T-treated male $>$ untreated male, $p<0.002$.

Pebble pecks; T-treated male $>$ untreated male, $0.002<p>0.02$, [125].

specifications persist longer for animals with circulating androgens.

Broverman provides similar evidence for men [24]. Thus male college students with high androgen levels performed well on a task involving the recognition of a limited number of objects that were repeatedly presented. These students' scores did not differ from the mean of the group on a similar task involving the speed of naming non-repeated objects. The first task requires a limited set of specifications, the latter requires that the specifications be continually changed. It has also been shown that during infusion with high but physiological levels of testosterone men were better able at continuing mental arithmetic in which a running total had to be maintained [83]. This additionally indicates a decreased distractibility, that would otherwise disrupt performance. It has also been suggested that this decreased ability to change central specifications would account for the longer period taken by men with hig $h$ levels of androgen to locate a given pattern within a larger pattern. The embedded figures task is one of the few that has also been used with women. Their performance will now be discussed.

\section{Estrogen}

It is unfortunate that there has been no systematic follow up of the chick work with estrogens that has been published and that there have been so few recent investigations about the effects of hormones circulating in female animals other than the human species. As noted above testosterone injected into female animals does not produce similar effects on behavior to the injection of males.

One task that has proved useful is the ability to detect two flashes of light as two and not one flash, as the interval between them is decreased. Thresholds are high and thus performance poor during the premenstrual period of women[$[39,85]$. Signal detection analysis in naturally cycling women [39] and women receiving synthetic estrogen and progesterone medication [173] shows that changes of hor- mone levels can result in changes of sensory sensitivity and criterion placement [173] depending on the nature of the instructions for the task. It may not be worthwhile to concentrate too much on sensory sensitivity changes in the light of the plausible suggestion that progesterone withdrawal and water retention may be linked to corneal edema [161]. This report cited clinical findings on impaired vision in the premenstrual period. Nonetheless there are reports that the detection of test stimuli is best (i.e., equivalent to men and to women using contraceptive pills) at mid-cycle when estrogen is high in the visual [42], olfactory [85] and auditory [141] modalities. It would seem questionable if all these modalities were to be improved at the peripheral level by changes of progesterone levels.

There are conflicting reports on the hormonal influence over criterion placement $[39,161]$ and a range of possible interpretations for the improved visual discrimination in the premenstrual period that has been reported [161]. However the improvement of subjects in reducing responsiveness to irrelevant stimuli when estrogen levels are declining seems to be just the characteristic required by women on an embedded figures task. Broverman comments that their performance $[24,25]$ is poor (with respect to men) because they show difficulty in delaying response tendencies to obvious (irrelevant) stimulus attributes. But of course we know nothing of the estrogen levels of these women. This hypothesis is worth pursuing because it might demonstrate influences of different levels of estrogen as well as different levels of testosterone on persistence.

Women take longer than male samples (not controlled for level of testosterone) to solve an embedded figures task [151, $171,172]$. Conceivably this may not be a function of estrogen levels but rather the absence of testosterone, for children are also reported to take a long time to solve such tasks [164]. Performance in terms of a perceptual adherence to the contours has been described for both women and children $[164,171]$. As has been suggested for ACTH experiments, above, tests for the ability to categorise (e.g., match to sample) should be introduced to clarify the issue. The distinction 
between conceptual and perceptual performance has otherwise become confused. To what extent this distinction has explanatory value in attention awaits further testing.

Investigation of on the one hand similar effects of high levels of testosterone and lower normal estrogen levels and on the other hand the established contrasting sex differences has been furthered by recent studies on the different effects of ACTH on males and females. Neonatal treatment with $\mathrm{ACTH}_{4-9}$ exaggerates the sexual tendencies. Female rats showed an enhanced position orientation (not adaptive for the visual discrimination) whereas males showed increased visual orientation and reversal learning ability [31]. This study was followed by one with women that showed that $\mathrm{ACTH}_{4-10}$ injected women in mid-cycle (estrogen high) showed impaired reversal learning abilities [157]. It appears that the peptide can promote the effects of the sex steroids (as if they were present at high levels), namely promoting persistence of acquired strategies, that do not help the solution of reversal tasks.

There are many other studies discussing the differences of perceptual and motor performance between the sexes (see [25] for a review) that are not treated here as their relevance to attention rather than other roles is unclear. Too often differences can be ascribed to a class of subjects but not to the hormones circulating. The work on hormones discussed relates to their activational effects. Such hormones may also have organisational influences on the structures involved in attentive and cognitive abilities. Male rats make fewer errors than females in a Hebb-Williams maze. Gonadectomy may reverse the normal differences in the levels of activity in an open field, but surgery does not affect maze performance $[38,86]$. Such differences along with some human sex differences may reflect differences in the organisation of cortical function related to the differential rates of physical maturation [160]. For example those that mature early have better spatial and verbal abilities than late developers [160]. Visuospatial abilities are more dominant in males and verbal abilities more dominant in females [70]. Although child rearing practices will have an important role, it should also be pointed out that potential interactions between a rise in steroid hormones with heterogonic development in the brain has not been adequately taken into account in experimental design.

\section{CONCLUSIONS}

At the start of this review the thesis was put forward that the selection of different attributes of a stimulus or of different stimuli is not only a result of peripheral mechanisms. The availability of inputs for registration is significantly under the control of the physiological state of the animal and the chance that the stimulus comes to control behavior is restricted by previously acquired and registered information. In this article a comparator mechanism is seen to have a part in the process of attention and evidence is reviewed that supports a role for the hippocampal-septal axis in processes essential for a comparator mechanism (selecting information for matching and registration). There are tendencies within the hippocampal-septal axis, from other limbic structures and from hormonal levels to direct attention (and consequent registration) to relevant and significant features; "the fixing of attention" [74]. The hormones have a modulatory role that depends on the external conditions and the internal state of the organism. Thus ACTH can be excitatory when novelty appears yet inhibitory with prolonged stimulus presentation. The state of the organism can determine gonadal steroid levels that also inhibit the changing of central specifications for matching and thus facilitate persistence.

There is direct evidence for considering that the hippocampus and septum, adrenocortical and gonadal hormones have an interconnected role. Lesion and stimulation of the limbic system affects circulating levels of these hormones. These hormones are taken up in the intact limbic system and some are shown to modify electrophysiological activity and the content of biogenic amines of the limbic system.

Less direct is the range of evidence that they are among the biological bases that are important in attention control. There have been more direct tests of attention in humans than in other animals and more investigations of pertinent hormonal influences than of animal lesions on attention. This situation probably results from the historical emphasis of psychologists on affective changes in the former instance and of animal behaviorists on learning theory in the latter instance. However this review finds considerable support for these biological bases in attention systems from recent "interdisciplinary" studies that have concentrated more on the nature of the stimulus control of behavior.

Thus traditional learning deficits of rats with hippocampal lesions can be reversed in some cases by the manipulation of sensory cues. The impairment of septally lesioned animals depends on the number of sensory cues and strategies available. Hippocampal theta activity correlates with periods when the animal aquires, relates and identifies sensory input [84]. This direction of emphasis is converging on that followed by those studying hormonal influences on performance. Thus levels of carbohydrate active steroids and female hormones affect the ability to detect and recognise stimuli. Once recognised they may persist (e.g., under high levels of testosterone) in controlling behavior. There are certain behavioral characteristics of animals with septal and hippocampal damage that have been interpreted as "locking on" to a stimulus. It is still an open question amenable to testing whether these two effects are coincidences of description or share a related cause.

Some of the evidence discussed consists of correlation and can be interpreted in more than one way. This state exists whilst ideas such as persistence have seldom been expressed as part of an attention process and thus not subjected to specific testing. Much of the physiological evidence reviewed shows that the recognition of sensory input and its registration does seem to employ certain rules as suggested by Haber and Hershenson [64]. The interactions of the hippocampal-septal axis and the pituitary-adrenal-gonadal axes influence how these rules are executed.

It has been the purpose of this paper to raise questions and to stimulate further investigations into the role of hormones and the limbic systems in attention processes. Perhaps it is not too remote a probability to be able to relate neurophysiological concomitants of attention processes directly to search behavior; that attention does become an overt and observable phenomenon that it has for too long been supposed not to be. 


\section{REFERENCES}

1. Adey, W. R. The sensorium and the modulation of cerebral states: tonic environmental influences on limbic and related systems. Paper presented at PNAS meeting on Tonic functions of sensory systems, 1977.

2. Adey, W. R., C. W. Dunlop and C. E. Hendrix. Hippocampal slow waves: distribution and phase relationships in the course of approach learning. Archs Neurol. 3: 14-90, 1960.

3. Anchel, H. and D. B. Lindsley. Differentiation of two reticular-hypothalamic systems regulating hippocampal activity. Electroenceph clin. Neurophysiol. 32: 209-232, 1972.

4. Andrew, R. J. Changes in search behaviour in male and female chicks following different doses of testosterone. Anim. Behav. 20: 741-750, 1972.

5. Andrew, R. J. Recognition processes and behaviour with special reference to effects of testosterone on persistence. $A d v$. Stud. Behav. 4: 175-208, 1972.

6. Andrew, R. J. Attentional processes and animal behaviour. In: Growing Points in Ethology, edited by R. A. Hinde and P. P. G. Bateson. Cambridge: Oxford University Press, 1976, pp. 95-133.

7. Andrew, R. J. and L. J. Rogers. Testosterone, search behaviour and persistence. Nature 237: 343-346, 1972.

8. Archer, $J$. The influence of testosterone on chick behaviour in novel environments. Behav. Biol. 8: 93-108, 1973.

9. Archer, J. A further analysis of responses to a novel environment by testosterone treated chicks. Behav. Biol. 9: 389-396, 1973.

10. Archer, J. The effects of testosterone on distractibility of chicks by irrelevant and relevant novel stimuli. Anim. Behav. 22: $397-404,1974$

11. Archer, J. Testosterone and behaviour during extinction in chicks. Anim. Behav. 22: 650-655, 1974

12. Archer, J. Testosterone and persistence in mice. Anim. Behav. 25: 479-489, 1977.

13. Beckwith, B. E., C. A. Sandman and A. J. Kastin. Influence of three short chain peptides (aMSH, MSH/ACTH ${ }_{4-110}$, MIF-I) on dimensional attention. Physiol. Behav. 18: 63-71, 1977.

14. Bengelloun, W. A., D. J. Nelson, H. M. Zent and W. M. Beatty. Behavior of male and female rats with septal lesions: influence of prior gonadectomy. Physiol. Behav. 16: 317-330, 1976.

15. Bennett, T. L. Hippocampal theta activity and behavior. Communs behav. Biol. 6: 37-48, 1971.

16. Bennett, T. L., J. French, K. N. Burnett. Species differences in the behavioral correlates of hippocampal RSA. Behav. Biol. 22: $161-177,1978$.

17. Bland, B. H. and I. Q. Whishaw. Generators and topography of hippocampal theta (RSA) in the anaesthetised and freely moving rat. Brain Res. 118: 259-280, 1976.

18. Bohus, B. The effect of central nervous lesions on pituitaryadrenocortical function in the rat. Acta physiol. acad. scient. hung. 20: 373-378, 1961.

19. Bohus, B. Central nervous structures and the effect of ACTH and corticosteroids on avoidance behaviour: a study with intracerebral implantation of corticosteroids in the rat. In: Pituitary, Adrenal and the Brain, edited by D. de Wied and J. A. W. M. Weijner. Amsterdam: Elsevier, Prog. Brain Res. 32: $171-183,1970$

20. Bohus, B. The hippocampus and the pituitary adrenal system hormones. In: The Hippocampus, edited by R. L. Isaacson and K. H. Pribram. New York: Plenum Press, 1975, pp, 323-353.

21. Bohus, B., C. Nyakas and K. Lissak. Involvement of suprahypothalamic structures in the hormonal feedback action of corticosteroids. Acta physiol. acad. scient. hung. 34: 1-8, 1968.

22. Bohus, B., Tj. B. Wimersma Greidanus and D. de Wied. Behavioral and endocrine responses of rats with hereditary diabetes insipidus (Brattleboro strain). Physiol. Behav. 14: 609-615, 1975.
23. Bremner, F. J. Hippocampal electrical activity during classical conditioning. J. comp. physiol. Psychol. 66: 35-39, 1968.

24. Broverman, D. M., I. K. Broverman, W. Vogel, R. D. Palmer and E. L. Klaiber. The automatisation cognitive style and physical development. Child develop. 35: 1343-1359, 1964.

25. Broverman, D. M., E. L. Klaiber, Y. Kobayashi and W. Vogel. Roles of activation and inhibition in sex differences in cognitive abilities. Psychol. Rev. 75: 23-50, 1968.

26. Brown, B. B. Frequency and phase of hippocampal theta activity in the spontaneously behaving cat. Electroenceph. clin. Neurophysiol. 24: 53-62, 1968.

27. Brugge, J. F. An electrographic study of the hippocampus and neocortex in unrestrained rats following septal lesions. Electroenceph. clin. Neurophysiol. 18: 38-44, 1965.

28. Buchsbaum, M. and A. Pfeifferbaum. Individual differences in stimulus intensity response. Psychophysiology 8: 600-611, 1971.

29. Carillo, A. J. and J. D. Dunn. The effect of amygdaloid ablation or stimulation on plasma corticosterone levels in the male rat. Neuroscience 2: 997-1006, 1977.

30. Casady, R. L. and A. N. Taylor. Effect of electrical stimulation of the hippocampus upon corticosteroid levels in the freely behaving non-stressed rat. Neuroendocrinology 20: 68-78, 1976.

31. Champney, T. F., T. L. Sahley and C. A. Sandman. Effects of neonatal cerebral ventricular injection of $\mathrm{ACTH}_{4}$ and subsequent adult injections in male and female albino rats. Pharmac. Biochem. Behav. 5: Suppl. 1, 3-11, 1976.

32. Coppola, A. A. Turnover of hypothalamic catecholamines during various stages of gonadotropin secretion. Neuroendocrinology 5: 75-80, 1969.

33. Cottrell, G. A. and S. Nakajima. Effects of corticosteroids in the hippocampus on passive avoidance behavior in the rat. Pharmac. Biochem. Behav. 7: 277-280, 1977.

34. Crowley, W. R., T. L. O'Donohue and D. M. Jacobowitz. Changes in catecholamine content in discrete brain nuclei during the estrus cycle of the rat. Brain Res. 147: 315-326, 1978.

35. Dabrowska, J. and B. Maj. Deficit in postoperative learning and retention of complex tasks by septal rats. Acta Neurobiol. Exp. 38: 31-44, 1978.

36. Davidson, J. M. and S. Feldman. Effects of extrahypothalamic dexamethasone implants on the pituitary adrenal system. Acta Endocr. 55: 240-246, 1967.

37. Dawkins, M. Shifts of 'attention' in chicks during feeding. Anim. Behav. 19: 575-582, 1971

38. Dawson, J. L. M., Y. M. Cheung and R. T. S. Lau. Effects of neonatal sex hormones on sex based cognitive abilities in the white rat. Psychologia 16: 17-24, 1973.

39. De Marchi, G. W. and J. E. Tong. Menstrual, diurnal and activation effects on the resolution of temporally paired flashes. Psychophysiology 9: 362-367, 1972.

40. De Wied, D. Peptides and behavior. Life Sci. 20: 195-204, 1977.

41. De Wied, D. and B. Bohus. Long term and short term effects on retention of a conditioned avoidance response by rats by treatment with long acting pitressin and MSH. Nature 213: $1484-1486,1966$

42. Diamond, M., A. L. Diamond and M. Mast. Visual sensitivity and sexual arousal levels during the menstrual cycle. $J$. nerv. ment. Dis. 155: 170-176, 1972.

43. Doerr, P. and K. M. Pirke. Cortisol induced suppression of plasma testosterone in normal adult males. $J$. clin. Endocr. Metab. 43: 622-628, 1976.

44. Donoso, A. O. and F. J. Stefano. Sex hormones and concentration of noradrenaline and dopamine in the anterior hypothalamus of castrated rats. Experientia 23: 665-666, 1967.

45. Donovick, P. J., R. G. Burright, R. D. Sikorszky, N. J. Stamato and $W$. W. Maclaughlin. Cue elimination effects on discrimination behaviour of rats with septal lesions. Physiol. Behav. 20: 71-78, 1978. 
46. Douglas, R. J. Pavlovian conditioning and the brain. In: Inhibition and Learning, edited by R. A. Boakes and M. S. Halliday. London: Academic Press, 1972, pp. 529-553.

47. Douglas, R. J. and K. H. Pribram. Learning and limbic lesions. Neuropsychologia 4: 197-220, 1966.

48. Douglas, R. J., T. W. Barrett, K. H. Pribram and M. C. Cerny. Limbic lesions and error reduction. J. comp. physiol. Psychol. 68: $437-441,1969$.

49. El Halawani, M. E. and W. H. Burke. Brain monoamine metabolism of Turkey hens in various stages of their reproductive life cycle. Biol. Reprod. 15: 254-259, 1976.

50. Endroczi, E., K. Lissak, T. Fekete and D. de Wied. Effects of ACTH on EEG habituation in human subjects. Prog. Brain Res. 32: 254-262, 1970.

51. Engel, G. L. and S. G. Margolin. Neuropsychiatric disturbances in Addison's disease and the role of impaired carbohydrate metabolism in the production of abnormal cerebral function. Archs. Neurol. Psychiat. 45: 881-884, 1941.

52. Ewert, J.-P. The visual system of the toad: behavioural and physiological studies on a pattern recognition system. In: The Amphibian Visual System. New York: Academic Press, 1976, pp. 142-200.

53. File, S. E. Raised brain GABA levels, motor activity and exploration in the rat. Brain Res. 131: 180-183, 1977.

54. Gillard, A. W. K. and A. F. Sanders. Some effects of $\mathrm{ACTH}_{4-10}$ on performance during a serial reaction task. Psychopharmacologia 42: 201-208, 1975.

55. Gavalas, R. J., D. O. Walter, J. Hamer and W. R. Adey. Effects of low level. Low frequency electrical fields on EEG and behavior in Macaca nemestrina. Brain Res. 18: 491-501, 1970.

56. Glosser, G., N. Butters and I. Samuels. Failures in information processing in patients with Korsakoff's syndrome. Neuropsychologia 14: 327-334, 1976.

57. Goldstone, S. and N. T. Lhamon. The effects of haloperidol upon temporal information processing by patients with Tourette's syndrome. Psychopharmacology 50: 7-10, 1976.

58. Gray, J. A. Medial septal lesions, hippocampal theta rhythm and the control of vibirissa movement in the freely moving rat. Electroenceph. clin. Neurophysiol. 11: 481-490, 1971.

59. Gray, J. A. The effects of septal driving on the hippocampal theta rhythm on resistance to extinction. Physiol. Behav. 8: $481-490,1972$.

60. Gray, J. A. and G. G. Ball. Effect of experimental control of hippocampal theta rhythm on learning and extinction in free moving rats. Electroenceph. clin. Neurophysiol. 27: 663-673, 1969.

61. Gray, J. A., L. Rickwood, R. F. Drewett and E. Dunne. Gonadal hormones and effects of partial reinforcement on appetitive behavior in the rat. Physiol. Behav. 19: 41-45, 1977.

62. Grastyan, E., K. Lissak, I. Madrasz and H. Donhoffer. Hippocampal electrical activity during the development of conditioned reflexes. Electroenceph. clin. Neurophysiol. 11: 409 $430,1959$.

63. Green, J. D. and A. A. Arduini. Hippocampal electrical activity in arousal. $J$. Neurophysiol. 17: 533-557, 1954.

64. Haber, R. N. and M. Hershenson. The Psychology of Visual Perception. New York: Holt, Rinehart and Winston, 1973.

65. Han, M. F. and P. J. Livesey. Brightness discrimination learning under conditions of cue enhancement by rats with lesions in the amygdala or hippocampus. Brain Res. 125: 277-292, 1977.

66. Hanfman, E. A study of personal patterns in an intellectual performance. Charact. Pers. 9: 315-325, 1941.

67. Haun, C. K. and G. C. Haltmeyer. Effects of intraventricular injection of synthetic ACTH on plasma testosterone, progesterone and LH levels and on sexual behavior in male and female rabbits. Neuroendocrinology 19: 201-213, 1975.

68. Henkin, R. 1. The neuroendocrine control of perception. In: Perception and Its Disorders, edited by D. A. Hamburg, K. H. Pribram and A. J. Stunkard. Baltimore: Williams and Wilkins, 1970 , pp. 54-107, Vol. 48.

69. Holzbauer, M. Physiological properties of the hypnotic aspects of steroid hormones. Br. J. Pharmac. 56: 382-383, 1976.
70. Hutt, C. Males and Females. Baltimore: Penguin, 1972.

71. Isaacson, R. L. The Limbic System. New York: Plenum Press, 1974.

72. Isaacson, R. L. and D. P. Kimble. Lesions of the limbic system: their effect upon hypotheses and frustration. Behav. Biol. 7: 767-793, 1972.

73. Isaacson, R. L., A. J. Dunn, D. D. Rees and B. Waldock. $\mathrm{ACTH}_{4-10}$ and improved use of information in rats. Physiol. Psychol. 4: 159-162, 1976.

74. Iversen, S. D. Do hippocampal lesions produce amnesia in animals? Int. Rev. Neurobiol. 19: 1-49, 1976.

75. Kaada, B. R., R. S. Feldman and T. Langfeldt. Failure to modulate autonomic reflex discharge by hippocampal stimulation in rabbits. Physiol. Behav. 7: 225-231, 1971.

76. Kastin, A. J., L. H. Miller, D. Gonzalez-Barcena, W. D. Hawley, H. K. Dyster-Aas, A. V. Schally, M. L. V. Parra and M. Velasco. Psychophysiologic correlates of MSH activity in man. Physiol. Behav. 7: 893-896, 1971.

77. Kawakami, M., K. Seto and K. Yoshida. Influence of corticosterone implantation in limbic structures upon biosynthesis of adrenocorticosteroid. Neuroendocrinology 3: 349-354, 1968.

78. Keefer, D. A. and W. E. Stumpf. Atlas of estrogen concentrating cells in the central nervous system of the Squirrel monkey. J. comp. Neurol. 160: 419-442, 1975.

79. Kelley, D. B., J. I. Morrell and D. W. Pfaff. Autoradiographic localisation of hormone concentrating cells in the brain of an amphibian, Xenophus laevis; I Testosterone. J. comp. Neurol. 164: 47-62, 1975.

80. Kemp, I. R. and B. R. Kaada. The relation of hippocampal theta activity of arousal, attentive behaviour and somato-motor movements in unrestrained cats. Brain Res. 95: 323-342, 1975.

81. Kimble, D. P. Hippocampus and internal inhibition. Psychol. Bull. 70: 285-295, 1968.

82. Kimble, D. P. and R. J. Kimble. The effect of hippocampal lesions on extinction and "hypothesis" behavior in the rat. Physiol. Behav. 5: 735-738, 1970.

83. Klaiber, E. L., D. M. Broverman, W. Vogel, G. E. Abraham and F. L. Cone. The effects of infused testosterone on mental performance and serum L.H.J. clin. Endocr. Metab. 32: 341$350,1971$.

84. Komisaruk, B. The role of rhythmical brain activity in sensorimotor integration. Prog. Psychobiol. Physiol. Psychol. 7: 55-90, 1977.

85. Kopell, B. S., D. T. Lunde, R. B. Clayton and R. H. Moos. Variations in some measures of arousal during the menstrual cycle. J. nerv. ment. Dis. 148: 180-187, 1969.

86. Krasnoff, A. and L. M. Weston. Puberal status and sex differences: activity and maze behavior in rats. Dev/ Psychobiol. 9: 261-269, 1976.

87. Krechevsky, I. "Hypotheses" in rats. Psychol. Rev. 39: 516$532,1932$.

88. Krieger, D. T., A. Liotta and M. J. Brownstein. Presence of corticostropin in limbic system of normal and hypophysectomised rats. Brain Res. 128: 575-579, 1977.

89. Laughlin, M. E., P. J. Donovick and R. H. Burright. Septal lesions in meadow voles and mongolian gerbils: consummatory and investigatory behavior. Physiol. Behav. 15: 191-198, 1975.

90. Lengvari, I. and Z. Liposits. Diurnal changes in endogenous corticosterone content of some brain regions of rats. Brain Res. 124: 571-575, 1977.

91. Leppelsack, H. J. and M. Vogt. Responses of auditory neurons in the forebrain of a song bird to stimulation with speciesspecific sounds. J. comp. Physiol. 107: 263-274, 1976.

92. Leshner, A. I. A model of hormones and agonistic behavior. Physiol. Behav. 15: 225-235, 1975.

93. Löfström, $A$. and $T$. Bäckström. The relationship between Plasma estradiol and brain catecholamine content in the diestrus female rat. Psychoneuroendocrinology 3: 103-107, 1978.

94. Luton, J.-P., P. Thieblot, J.-C. Valcke, J. A. Mahoudeau and $\mathrm{H}$. Bricaire. Reversible gonadotropin deficiency in male Cushing's disease. J. clin. Endocr. Metab. 45: 488-495, 1977. 
95. Mackintosh, N. J. Incidental cue learning in rats. $O . J$ exp Prychol. 17: 292-300, 1965

96. Martinez-Vargas, M. C., W. E. Stumpf and M. Sar. Anatomical distribution of estrogen target cells in the avian CNS: a comparison with the mammalian CNS. J. comp. Neurol. 167: 83-104, 1976

97. Martinez-Vargas, M. C., D. A. Keefer and W. E. Stumpf. Estrogen localisation in the brain of the lizard, Anolis carolinensis. J. exp. Zool. 205: 141-147, 1978.

98. Mezey, E., M. Palkovits, E. R. de Kloet, J. Verhoef and D. de Wied. Evidence for pituitary brain transport of a behaviorally potent ACTH analog. Life Sci. 22: 831-838, 1978

99. McEwen, B. S. and G. Wallach. Corticosterone binding to hippocampus: nuclear and cytosol binding in vitro. Brain Res. 57: 373-386, 1973 .

100. McEwen, B. S., J. M. Weiss and L. S. Schwartz. Retention of corticosterone by cell nuclei from brain regions of adrenalectomised rats. Brain Res. 17: 471-482, 1970.

101. Miller, L. H., A. J. Kastin, C. A. Sandman, M. Fink and W. J van Ween. Polypeptide influences on attention, memory and anxiety in man. Pharmac. Biochem. Behav. 2: 663-668, 1974.

102. Miller, L. H., L. C. Harris, H. van Riezen and A. J. Kastin. Neuroheptapeptide influences on attention and memory in man. Pharmac. Biochem. Behav. 5: Suppl. I, 17-23, 1976.

103. Miller, R. J. Enkephalin: a peptide with morphine-like properties. Trends Neurosci. 1: 29-31, 1978.

104. Mirsky, A. F. and M. M. Orren. Attention. In: Neuropeptide Influences in the Brain, edited by L. H. Miller, C. A. Sandman and A. J. Kastin. New York: Raven Press, 1977, pp. 233-267.

105. Morrell, J. I., D. B. Kelley and D. W. Pfaff. Sex steroid binding in the brains of vertebrates. In: The Ventricular System, edited by K. M. Knigge, D. E. Scott, M. Kobayashi and S. Ishi.. Proceedings of the second Brain Endocrine interaction symposium. Basel: Karger, 1975, pp. 230-256.

106. Murawski, B. J. and S. K. Burns. Daily correlation of adrenal steroids and alpha frequency in the EEG: a demonstration. $J$. appl. Physiol. 21: 549-553, 1966.

107. Oades, R. D. A persistence of responding in hyperstriatal chicks. Behar. Biol. 18: 235-262, 1976.

108. Oades, R. D. A persistence of the pattern of feeding in chicks with hyperstriatal lesions. Brain Behav. Evolut. 13: 69-91, 1976.

109. Oades, R. D. More persistence during task acquisition by intact vs castrated Japanese quail. Poultry Sci. 57: 821-822, 1978.

110. Oades, R. D. Approach to auditory signals: an analysis of persistence in the Guinea fowl after hyperstriatal lesion. In submission.

111. Oades, R. D. and R. L. Isaacson. PCPA-produced effects on behaviour in intact and brain-damaged rats. Behav. Biol. 20: $500-506,1977$

112. Oades, R. D, and R. L. Isaacson. The development of food search behavior by rats: the effects of hippocampal damage and haloperidol treatment. Behav. Biol. 24: 327-337, 1978.

113. O'Keefe, J. and L. Nadel. The Hippocampus as a Cognitive Map. London: Oxford University Press, 1978.

114. Olds, J. Learning and the hippocampus. Rev. Can. Biol. 31: Suppl., 215-238, 1972.

115. Pacold, S. T., L. Kirsteins, S. Hojvat, A. M. Lawrence and T. C. Hagen. Biologically active pituitary hormones in the rat brain amygdaloid nucleus. Science 199: 804-806, 1978

116. Pfaff, D. W., M. T. A. Silva and J. M. Weiss. Telemetrical recording of hormonal effects on hippocampal neurons. Science 172: 394-395, 1971.

117. Pickenhain, L. and F. Klingberg. Hippocampal slow wave activity as a correlate of basic behavioral mechanisms in the rat. In: Structure and Function of the Limbic System, edited by W. R. Adey and T. Tokizane. Prog. Brain Res. 27: Amsterdam: Elsevier, 1967, pp. 218-227.

118. Pribram, K. H. and R. L. Isaacson. Summary. In: The Hippocampus, edited by R. L. Isaacson and K. H. Pribram. New York: Plenum Press, 1975, pp. 429-440.
119. Pribram, K. H. and D. McGuinness. Arousal, activation and

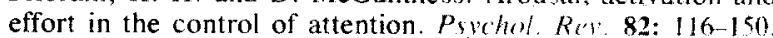
1975.

120. Raemakers, F., H. Rigter and B. E. Leonard. Parallel changes in behavior and hippocampal serotonin metabolism in rats following treatment with desglycinamide lysine vasopressin. Brain Res. 120: 485-492, 1977

121. Rastogi, R. B. and R. L. Singhal. Evidence for the role of adrenocortical hormones in the regulation of noradrenaline and dopamine metabolism in certain brain areas. $\mathrm{Br} . \mathrm{J}$. Pharmat. 62: $131-136,1978$.

122. Rickert, E. J., T. L. Bennett, P. Lane and J. French. Hip pocampectomy and the attenuation of blocking. Behar. Biol. 22: $147-160,1978$

123. Riezen, $H$. van, $H$. Rigter and D. de Wied. Possible significance of ACTH fragments for human mental perform ance. Behal. Biol. 20: 311-324, 1977.

124. Roberts, D. C. S., M. T. C. Price and H. C. Fibiger. The dorsal tegmental noradrenergic projection: an analysis of its role on maze learning. J. comp. physiol. Psychol. 90: 363-372, 1976.

125. Rogers, L. J. Persistence and search influenced by natural levels of androgens in young and adult chickens. Physiol. Behav. 12: 197-204, 1974.

126. Rose, J. D. and R. P. Michael. Facilitation by estradiol of midbrain and ponteine unit responses to vaginal and somatosensory stimulation in the Squirrel monkey (Saimiri sciureus). Exp. Neurol. 58: 46-58, 1978.

127. Rubin, R. T., A. J. Mandell and P. H. Crandall. Corticasteroid responses to limbic stimulation in man: localisation of stimufus sites. Science 153: 767-768, 1966.

128. Runnebaum, B., J. Heep, W. Geiger, P. Vecsei and J. Andor. Effect of aMSH on plasma levels of LH, FSH, progesterone and cortisol during the corpus luteum phase of the menstrual cycle. Acta Endocr. 81: 243-251. 1976.

129. Sandman, C. A., A. J. Kastin and A. V. Schally. Behaviora inhibition as modified by melanocyte stimulating hormone (MSH) and light dark conditions. Physiol. Behar. 6: $45-48$, 1971.

130. Sandman, C. A., W. D. Alexander and A. J. Kastin. Neuroendocrine influences on visual discrimination and reversal learning in the albino and hooded rat. Physiol. Behav. 11: 613-617. 1973.

131. Sandman, C. A., L. H. Miller, A. J. Kastin and A. V. Schally Neuroendocrine influences on attention and memory. $J$. comp. physiol. Psychol. 80: 54-58, 1972.

132. Sandman, C. A., J. M. George, J. D. Nolan, H. van Riezen and A. J. Kastin. Enhancement of attention in man with $\mathrm{ACTH} / \mathrm{MSH}_{4,11}$ Physiol. Behav. 15: 427-431, 1975

133. Sandman, C. A., J. George, J. D. Walker, J. D. Nolan and A. J Kastin. Neuropeptide MSH/ACTH M $_{4}$ enhances attention in the mentally-retarded. Pharmac. Biochem. Behav. 5: Suppl. 1 , 23-29, 1976

134. Sandman, C. A., P. M. Denman, L. H. Miller, J. R. Knott, A. V. Schally and A. J. Kastin. Electroencephalographic measures of melanocyte stimulating hormone activity. $J . \mathrm{comp}$. physiol. Psychol. 76: 103-107, 1971

135. Sandman, C. A.. J. George, T. R. McCanne, J. D. Nolan, J

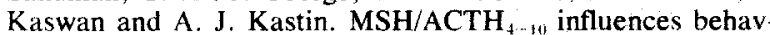
ioral and physiological measures of attention. J. clin. Endorr. Metab. 44: 884-891, 1977

136. Scheich, H. Central processing of complex sounds and feature analysis. In: Recognition of Complex Acoustic Signals, edited by T. H. Bullock. Dahlem Knoferenzen: Life Sciences Research Reports 5: 1977, pp. 161-182.

137. Schöneshöfer, M. and G. G. Wagner. Sex differences in corticosteroids in men. $J$. clin. Endocr. Metab. 45: 814-817, 1977.

138. Segal, M. Interactions of ACTH and norepinephrine on the activity of rat hippocampal cells. Neuropharmacotogy 15: $329-333,1976$. 
139. Segal, M. and F. E. Bloom. The action of norepinephrine in the rats' hippocampus III: Hippocampal cellular responses to locus coeruleus stimulation in the awake rat. Brain Res. 107: 499 $511,1976$.

140. Segal, M. and F. E. Bloom. The action of norepinephrine in the rat's hippocampus IV: The effects of locus coeruleus stimulation on evoked hippocampal unit activity. Brain Res. 107: 513-525, 1976.

141. Semizuk, B., S. Przesmycka and M. Pomykalski. O zmianach wrazliowsci sluckoweg w okresie eyklu menstrua cyjnego. (On changes of acoustic sensitivity during the menstrual cycle.) Pol. Tyg. Lek. 22: 586-588, 1967.

142. Shen, J.-T. and W. F. Ganong. The effects of variations in pituitary adrenal activity on dopamine- $\beta$-hydroxylase activity in various regions of the rat brain. Neuroendocrinology 20: 311-318, 1976.

143. Singer, W., J. Zihl and E. Poppel. Subocrtical control of visual thresholds in humans: evidence for modality specific and retinotopically organised mechanism of selective attention. Expl Brain Res. 29: 173-190, 1977.

144. Slusher, M. A. Effects of cortisol implants in the brain stem and ventral hippocampus on diurnal corticosteroid levels. Expl Brain Res. 1: 184-194, 1966.

145. Steele, Russell, I. Decorticate versus thalamic animals. Paper presented at the European Brain and Behaviour Society Workshop on the Neostriatum, Vingsted, April 1978.

146. Stumpf, W. E., M. Sar and D. A. Keefer. Atlas of estrogen target cells in the rat brain. In: Anatomical Neuroendocrinology, edited by W. E. Stumpf and L. D. Grant. Basel: Karger, 1975, pp. 104-119.

147. Sutherland, N. S. and N. J. Mackintosh. Mechanisms of Animal Discrimination Learning. New York: Academic Press, 1975.

148. Tanaka, M., D. H. G. Versteeg and D. de Wied. Regional effects of vasopressin on rat brain catecholamine metabolism. Neurosci. Lett. 4: 321-325, 1977.

149. Treisman, A. Strategies and models of selective attention. Psychol. Rev. 76: 282-229, 1969.

150. Tremmel, F., M. D. Morris and G. F. Gebhart. The effect of forebrain norepinephrine depletion on two measures of response suppression. Brain Res. 126: 185-188, 1977.

151. Tyler, L. E. The Psychology of Human Differences. New York: Appleton-Century-Crofts, 1956.

152. Urban, I. and D. de Wied. Changes in the excitability in the theta activity generating substrate by $\mathrm{ACTH}_{4-10}$ in the rat. Expl Brain Res. 24: 325-334, 1976.

155. Urban, I. and D. de Wied. Neuropeptides: Effects on paradoxical sleep and theta rhythm in rats. Pharmac. Biochem. Behav. 8: 51-59, 1978.

154. Urban, I., F. H. Lopes da Silva, W. Storm van Leeuwen and D. de Wied. A frequency shift in the hippocampal theta activity: an electrical correlate of central action of the ACTH analogues in the dog. Brain Res. 69: 361-365, 1974.

155. Usher, D. R., P. Kasper and M. X. Birmingham. Comparison of pituitary adrenal function in rats lesioned in different areas of the limbic system and hypothalamus. Neuroendocrinology 2: $157-326,1967$.

156. Van Hartesveldt, $C$. The hippocampus and regulation of the hypothalamic-hypophyseal-adrenal cortical axis. In: The Hippocampus, edited by R. L. Isaacson and K. H. Pribram. New York: Plenum Press, 1975, pp. 375-391.

\section{ADDENDUM}

Support for the interaction of hormones with the hippocampal-septal axis, connected areas and an association with information processing [6] continues to accrue. The presence of androgen receptors in the avian lateral septum [1] is confirmed and anatomical work supports the parallel
157. Veith, J. L., C. A. Sandman, J. M. George and V. C. Stevens. Effects of MSH/ACTH ${ }_{4-10}$ on memory, attention and endogenous hormone levels in women. Physiol. Behav. 20: 43-50, 1978.

158. Verhoef, J., A. Witter and D. de Wied. Specific uptake of a behaviorally potent ${ }^{3} \mathrm{H} \mathrm{ACTH}_{4-9}$ analog in the septal area after intraventricular injection in rats. Brain Res. 131: 117-128, 1977.

159. Vinogradova, O. S. Functional organisation of the limbic system in the process of registration of information: facts and hypotheses. In: The Hippocampus, edited by R. L. Isaacson and K. H. Pribram. New York: Plenum Press, 1975, pp. 3-69.

160. Waber, D. P. Sex differences in cognition: a function of maturation rate? Science 192: 572-574, 1976.

161. Ward, M. M., S. C. Stone and C. A. Sandman. Visual perception in women during the menstrual cycle. Physiol. Behav. 20: 239-243, 1978.

162. Warembourg, M. Radioautographic study of the rat brain after injection of 1,2- ${ }^{3} \mathrm{H}$ corticosterone. Brain Res. 89: 61-70, 1975.

163. Warembourg, M. Topographical distribution of oestrogenconcentrating cells in the brain and pituitary of the Squirrel monkey. Neurosci. Lett. 5: 315-319, 1977.

164. Werner, H. Progress and achievement. Harv. Educ. Rev. 7: 353-368, 1937.

165. Whishaw, I. Q., B. H. Bland, T. E. Robinson and C. H. Vanderwolf. Neuromuscular blockade: the effects on two hippocampal RSA (theta) systems and neocortical desyncrhonisation. Brain Res. Bull. 1: 573-581, 1976.

166. Wickelgren, W. O. and R. L. Isaacson. A relevant stimulus of runway performance of hippocampectomised rats. Nature 200: $40-48,1963$.

167. Wilson, C. L., B. C. Motter and D. B. Lindsley. Influences of hypothalamic stimulation upon septal and hippocampal electrical activity in the cat. Brain Res. 107: 55-68, 1976.

168. Wimersma Greidanus, T. B. van, B. Bohus and D. de Wied. Effects of peptide hormones on behaviour. In: Progress in Endocrinology, Proc. 4th Int. Congr. Endocr. Int. Congr. series No. 273, edited by R. Scow. Amsterdam: Excerpta Medica, 1973, pp. 284-289.

169. Wimersma Greidanus, T. B. van, B. Bohus and D. de Wied. CNS sites of action of ACTH, MSH and vasopressin in relation to avoidance behaviour. In: Anatomical Endocrinology, edited by W. E. Stumpf and L. D. Grant. Basel: Karger, 1975, pp. 284-289.

170. Winocur, G. and D. Bindra. Effects of additional cues on passive avoidance learning and extinction of rats with hippocampal lesions. Physiol. Behav. 17: 915-920, 1976.

171. Witkin, H. A. Individual differences in ease of perception of embedded figures. J. Personal. 19: 1-16, 1950.

172. Witkin, H. A., A. B. Dyk, H. F. Faterson, D. R. Goodenough and S. A. Karp. Psychological Differentiation. New York: John Wiley, 1962.

173. Wong, S. and J. Tong. Menstrual cycle and contraceptive hormonal effects on temporal discrimination. Percept. Mot. Skills 39: 103-108, 1974.

174. Wood-Gush, D. G. M., G. A. S. Langley, A. F. Leitch, M. J. Gentle and A. B. Gilbert. An autoradiographic study of sex steroids in the chicken telencephalon. Gen. comp. Endocr. 31: 161-168, 1977.

175. Yoshii, H. M., M. Schimokochi, K. Miyamoto and M. Ito. Studies on the neural bases of behavior by continuous frequency analysis of EEG. In: Correlative Neurosciences, $A$. Fundamental Mechanisms, edited by T. Tokizane and J. P. Schade. Prog. Brain Res. 21A: Amsterdam: Elsevier, 1966, pp. 217-250.

between the avian and mammalian hippocampal-septal axes postulated from behavioural studies, at least as far as connections of the precommissural fornix are concerned.

In rats there are vasopressin fibres that spread to the septum [5]. Here the vasopressin present [2], in the dorsal nuclei can decrease NA turnover [6]. By contrast the ab- 
sence of gonadal hormones in castrated rats causes a decrease in GABA levels in the septum [3]. These are physiological studies and may only be taken as suggestive of the means by which the hormones discussed in this article might exert their modulatory influences on attention-related pro cesses.

\section{ADDENDUM REFERENCES}

1. Barfield, R. J., G. Ronay and D. W. Pfaff. Autoradiographic localisation of androgen-concentrating cells in the brain of the male domestic fowl. Neuroendocrinology 26: 297-311, 1978.

2. Dogterom, J., F. G. M. Snijdewint and R. M. Buijy. The distribution of vasopressin and oxytocin in the rat brain. Neurosci. Lett. 9: 341-346, 1978.

3. Earley, C. J. and B. E. Leonard. GABA and gonadal hormones. Brain Res. 155: 27-34, 1978.
4. Krayniak, P. F. and A. Siegel. Efferent connections of the hippocampus and adjacent regions in the pigeon. Brain Behar. Evol. 15: 372-388, 1978.

5. Sofroniew, M. V. and A. Weindl. Projections of the parvocellular vasopressin- and neurophysin-containing neurons of the suprachiasmatic nucleus. Am. $J$. Anat. 153: 391-429, 1978.

6. Versteeg, D. H. G., M. Tanaka and E. R. De Kloet. Catecholamine concentration and turnover in discrete regions of the brain of the homozygous Brattleboro rat deficient in vasopressin. Endocrinology 103: 1654-1661, 1978. 